\title{
Climate Patterns: Origin and Forcing
}

\author{
Alexander Ruzmaikin \\ Jet Propulsion Laboratory, California Institute of Technology, Pasadena, USA \\ Email: alexander.ruzmaikin@jpl.nasa.gov
}

How to cite this paper: Ruzmaikin, A. (2021). Climate Patterns: Origin and Forcing. American Journal of Climate Change, 10, 204-236.

https://doi.org/10.4236/ajcc.2021.102010

Received: April 11, 2021

Accepted: June 27, 2021

Published: June 30, 2021

Copyright (c) 2021 by author(s) and Scientific Research Publishing Inc. This work is licensed under the Creative Commons Attribution International License (CC BY 4.0).

http://creativecommons.org/licenses/by/4.0/

\begin{abstract}
This brief review described spatial-time climate patterns generated by the dynamics and thermodynamics of the Earth's climate system and methods of identifying these patterns. Specifically, it does discuss the following major climate patterns: El Niño-Southern Oscillation (ENSO), Cold Ocean-Warm Land (COWL) pattern, Northern and Southern Annular Patterns (NAM and SAM), Atlantic Multidecadal Oscillation (AMO) and Atlantic Meridional Overturning Circulation (AMOC), Pacific North-American Pattern (PNA) and Pacific Decadal Oscillation Pattern (PDO). In view of an extensive number of publications on some climate patterns, such as the ENSO, which discussed in many hundred of publications, this review is not intended to cover all the details of individual climate patterns but intends only to give a general overview of their structure, mechanisms of their formation and response to external forcing. It is assumed that the climate patterns can be treated as attractors of dynamical systems allowing us to extract and predict some specific features of the patterns such as the origin and evolution of the climate patterns and their role in climate change. Thus the knowledge of patterns allows the climate prediction on long time scales and understanding of how an external forcing affects the frequency of occurrence of climate patterns and their magnitude but not the spatial structure.
\end{abstract}

\section{Keywords}

Spatial-Time Patters, Dynamics, Climate Change, Climate Prediction

\section{Introduction}

The observed temperature and other physical variables are not uniformly distributed over the Earth's surface, in its ocean and atmosphere. They are typically forming space-time clusters called weather and climate patterns. The ubiquitous and well-understood weather patterns are cyclones and anticyclones. A cyclone (Low) is a low-pressure pattern balanced by the pressure gradient and the Cori- 
olis force and rotating counterclockwise in the Northern Hemisphere and clockwise in the Southern Hemisphere. An anticyclone (High) has opposite sign of rotation. Highs and Lows are mobile and have short life-time lasting from days to maximum of two weeks. This review is about the long-term climate patterns. In the time domain, the Earth's climate system consists of two subsystems: the fast, "weather" type (mostly the atmosphere) and the slow one that includes the ocean and other slow-responding Earth's components (Hasselmann, 1976). The fast component can be averaged to serve as a source term to the slow system. The climate patterns arise as the major component of the slow subsystem.

The simplest climate pattern is the diurnal cycle. It is caused by the Earth's rotation around its axis and has the West-East symmetry. Daily (sunny) side of this pattern is warmer, nightly side is cooler. The time period of this pattern is one day. Another simple pattern is the seasonal pattern that appears due to the orbital motion of the Earth around the Sun. Its period is one year. The variability of the Earth's orbit on much longer time scale (the Milankovich cycles) creates orbital patterns (Loutre et al., 2004).

Sir Gilbert Walker (Walker, 1928) summarized anecdotal evidence on the teleconnections between weather in distant parts of the Earth and introduced three less-trivial large-scale coherent patterns that he called "swayings": North Atlantic Oscillation, North Pacific Oscillation, and Southern Oscillation covering the South Pacific and the Indian Ocean. Subsequently, numerous studies have demonstrated that the atmospheric and ocean variability on monthly and longer time scales is associated with these and other large-scale spatial-time patterns.

An example is the North Atlantic Oscillation (NAO), which was originally defined as a December-March mean of the sea level pressure difference between Iceland and Portugal (Hurrell, 1995). It is closely related to the Northern Annular Mode (NAM) (Thompson \& Wallace, 1998). The counterpart of the NAM in the Southern Hemisphere is called the SAM (Limpasuvan \& Hartmann, 2000).

Other examples of climate patterns include the Pacific-North America (PNA) pattern (Wallace \& Gutzler, 1981), the Cold Ocean-Warm Land (COWL) pattern (Wallace et al., 1995), the Pacific Decadal Oscillation (PDO) (Mantua et al., 1997), the well-known El Nińo-Southern Oscillation (ENSO) (Bjerknes, 1969; Timmermann et al., 2018), and the Quasi-Biennial Oscillation (QBO), which is observed in the stratosphere (Labitzke, 1987).

The climate patterns are associated with the low-frequency variability of the general circulation of the atmosphere and can be characterized by a small number of preferred circulations, often called "regimes". Observational evidence for the existence of the regimes was provided by Kimoto and Ghil (1993), who used the joint probability distribution functions (joint PDFs) of two leading modes identified from a principal component analysis of the $700 \mathrm{hPa}$ geopotential heights to find four hemispheric circulation regimes. Cheng and Wallace (1993) used a hierarchical cluster analysis technique to identify three preferred regimes of circulation in the North Hemisphere $500 \mathrm{hPa}$ flow. Corti et al. (1999) found several 
preferred flow regimes using model clustering and joint PDFs.

Here we briefly review the knowledge of characterization and origin of climate patterns and their role in climate change. We describe a set of major climate patterns, the physical mechanisms of their generation, and the external forcing of these patterns. There is an extensive number of publications on almost all major climate patterns, such as the ENSO and Annular patterns. This brief review is not intended to cover all the details of individual climate patterns and intends only to give a general overview of their structure, mechanisms of their formation and response to external forcing.

In Section 2 we outline the methods used for climate pattern identification. Section 3 presents a short notion of potential mechanisms generating the climate patterns. Section 4 represents a set of selected major climate patterns generated by atmospheric-ocean processes. We give a description of a climate pattern, followed by review of suggested mechanisms of its generation and the external influence on that pattern. Section 5 presents a discussion of pattern persistence and its possible role in long-term climate prediction.

\section{Methods of Pattern Identification}

There are well-developed methods of finding patterns in chaotic and deterministic systems. Here we describe the major methods used in climate studies.

\subsection{Principal Component Analysis (PCA)}

The most popular method is the Principal Component Analysis (PCA), originally invented by Karl Pearson (Pearson, 1901; Jolliffe, 2002; Jolliffe \& Cadima, 2016). The method employs the data in the form of a matrix $\boldsymbol{X}=\left(x_{1}(t), \cdots, x_{m}(t)\right)$, wherein the Earth case $X$ is a $m \times n$-dimensional vector usually presented by $m$ spatial pixels in a set of data maps taken at discrete times $t=1: n$. The idea is to seek a linear combination of the columns of matrix $X$ with maximum variance. The PCA is defined as an orthogonal linear transformation that transforms the data to a new coordinate system such that the greatest variance by some scalar projection of the data comes to lie on the first coordinate (called the first principal component), the second greatest variance on the second coordinate, and so on. The data in every pixel are typically centered, with the mean over time values $\sum$ and often normalized by standard deviations. The eigenvectors of the covariance matrix $X X^{\mathrm{T}}=n^{-1} \sum_{i=1}^{n}\left(x_{i}-\bar{x}\right)\left(x_{i}-\bar{x}\right)^{\mathrm{T}}$ are used to define the spatial and time parts of $k$ patterns, as well as their eigenvalues $\lambda$ s:

$$
X=\sum_{k} \lambda_{k} U_{k}(\boldsymbol{x}) V^{\mathrm{T}}(t),
$$

where

$$
X X^{\mathrm{T}} U_{k}=\lambda_{k} U_{k}, X^{\mathrm{T}} X V_{k}=\lambda_{k} V_{k},
$$

The $U(\boldsymbol{x})$ functions are usually called "Empirical Orthogonal Functions" (EOF) and $V(t)$ is called "Principal Components" (PCs). The term "empirical" 
emphasizes the fact that these functions determine the covariance (second-order correlations) between the observed spatial data points. It does not assume any physical causes of the covariance. The PCs can also be reconstructed using the data, EOFs and $\lambda \mathrm{s}$ :

$$
V_{k}(t)=X^{\mathrm{T}} U_{k} /\left(\lambda_{k}\right)^{1 / 2}
$$

The EOFs that result from the analysis often difficult to interpret in terms of physical processes. It might be beneficial to rotate the orthogonal basis to another basis, which can be better explained in terms of physical forces. Upon rotation, we will lose a nice property that EOFs have an orthogonal basis (no crosscorrelations between EOFs). We will perhaps also lose orthonormality of the EOFs matrix if we choose a non-orthogonal transformation of the data. It is also important to note that these rotations do not use any particular property of the EOFs (such as orthonormality) and you essentially reduce EOF analysis to noise reduction-via the reduction in the number of EOF-after performing these rotations. Some rotational methods retain the orthogonality of the modes but not the principal components or EOFs. Most commonly, the rotation has been used with the varimax code. The objective is to minimize the mode complexity by making the large loadings larger and the small loadings smaller (Jolliffe, 2002).

\subsection{Clustering Methods}

Another approach for pattern identification is the use of clustering methods. For example, the International Satellite Cloud Climatology Project used the K-means cluster technique (Hartigan, 1975) to identify cloud and weather regimes (Rossow et al., 2005). A cluster analysis had been applied to the CloudSat data from the A-train formation of satellites for identifying the type of clouds (Sassen \& Wang, 2008). Johnson and Feldstein (2010) used the K-means clustering to investigate the spatial and temporal variability of the wintertime North Pacific sea level pressure (SLP).

The K-means method uses $\mathrm{K}$ centers of clusters determined by minimizing the sum of squared errors of the data with a cost function

$$
J_{k}=\sum_{1}^{k} \sum_{j}\left(x_{j}-c_{k}\right)^{2}
$$

where $k$ is the number of clusters, $c_{k}=\sum_{j} x_{j} / n_{k}$ are the cluster centers with $n_{k}$ being the number of data points in the cluster $k$. The second sum (the sum over $j$ ) is taken over the data points in the cluster $k$.

As the next step in development of methods of data clustering preserving the information containing in the original data, Ruzmaikin and Guillaume (2014) explored a more advanced algorithm called Deterministic Annealing (Rose, 1998), which is based on the minimization of the cost function relative to two independent parameters (the distance between data points and the Shannon entropy of the data distribution) and provides probabilities with which data are associated with each cluster. The method has a close and deep analog to the clas- 
sical Gibbs' thermodynamics based on the use of a minimum two basic variables to define a thermodynamic state.

Ding and He (2014) investigated the relationship between the K-mean clustering and PCA to prove that Principal Components are the continuous solutions to the cluster membership indicators for $\mathrm{K}$-means clustering and to show that the subspace spanned by the cluster centers is given by spectral expansion of the data covariance matrix truncated at K-1 terms. This relationship strengthens the PCA and allows to equivalently using cluster methods in search for climate patterns.

A weak point of the Principal Component Analysis is that it is linear. It employs only the second-order correlations between data points, thus missing the high-order correlations. Monahan (2000) developed a nonlinear generalization of Principal Component Analysis, denoted as a Nonlinear Principal Component Analysis (NLPCA). NLPCA, as PCA, finds a data approximation by minimizing the mean squared error but, contrary to linear PCA, this approximation is not constrained to fall along a straight line in the space of the original variables. Rather, it can be a curve. A critical review of the PCA interpretation is given in Monahan et al. (2009).

Wu et al. (2009) introduce an approach for handling the full set of correlations between the data points, which they called "the Multidimensional Empirical Mode Decomposition (MEEMD)". In MEEMD, a time series at a grid point $x(t)$ is decomposed using Ensemble Empirical Mode Decomposition (Wu et al., 2009) into adaptively obtained, amplitude and frequency modulated oscillatory components and a residual, a curve either monotonic or containing only one extremum from which no additional oscillatory components can be extracted. For multi-dimensional spatial-temporal data, time scale components of data series from all grids are pieced together to form a temporal evolution of the spatially coherent structure of that timescale. In contrast to the PCA analysis, the MEEMD is a temporally and spatially local method, which provides a better chance to identify the underlying physical information provided by data. Recently new clustering methods based on machine learning were developed.

Thus a deep clustering is widely used in many practical applications for its powerful ability of feature extraction, it is natural to combine clustering algorithms with deep learning for better clustering results. Aljalbout et al. (2018); Min et al. (2018) gave systematic reviews of deep clustering from the perspective of network architectures and the representative algorithms to show the characteristics, advantages and disadvantages of different deep clustering algorithms. However, these powerful machine methods so far are only expected to be used in climate studies.

Donges et al. (2009) proposed a method based on a complex network to reconstruct and analyze data generated by a spatio-temporal dynamical system, relying on the nonlinear mutual information of time series analysis and betweenness centrality of the complex network theory. These authors indicated that 
the local degree centrality and related measures can be used to identify supernodes (regions of high degree centrality) and to associate them to known dynamical interrelations in the atmosphere called teleconnection patterns.

\section{Mechanisms of Pattern Formation}

The climate patterns are created by internal dynamics and thermodynamics of the Earth's climate system.

An important component of the dynamics is noise. Hasselmann (1976) introduced a model of climate variability driven by random noise excitation with short time scale ("weather") disturbances. Application of this model to sea-surface temperature (SST) (Frankignoul \& Hasselmann, 1977) and to zonally-averaged energy (Lemke, 1977) produced a red-noise response spectrum with the most of its variance concentrated at very long periods. However uncorrelated noise forcing does not generate any correlations necessary for creating spatial patterns.

The dynamics that include spatial correlations come from the Earth's rotation and large-scale waves. Carl-Gustaf Rossby (Rossby, 1939) was the first to emphasize the importance of the two main ingredients of the atmospheric dynamics: the zonal-mean zonal wind and non-zonally symmetric deviations of pressure or geopotential heights. He described the non-zonally symmetric deviations as waves, which are now known as "planetary waves" or "Rossby waves" (Holton, 2004). The air or the ocean fluid on the Earth that moves toward the pole will deviate east; a fluid (or air) moving toward the equator will deviate west (true in either hemisphere). This effect is caused by the Coriolis force and the conservation of the potential vorticity leading to changes of relative vorticity analogous to the conservation of angular momentum in mechanics. The phase speed of the Rossby waves is always directed from West to East and is

$$
c=\bar{u}-\frac{\beta}{k^{2}+l^{2}},
$$

where $u$ is the basic zonal speed, $\beta=2 \Omega \cos \varphi / R$ is the so-called Rossby parameter ( $\Omega$ is the Earth angular velocity, $R$ is the Earth radius, $k$ is the zonal wavenumber, and $l$ is the meridional wavenumber.) Thus Rossby waves owe their origin to the gradient of the tangential speed of the planetary rotation (planetary vorticity). The lowest wave mode (with the minimal $k=1$ ) changes its sign once over the $360^{\circ}$-long longitudinal circle.

The planetary waves are generated by winter flow over mountains and by sea-land temperature contrasts and propagate in horizontal and vertical directions (Charney \& Drazin, 1961). The vertical propagation of the waves into the stratosphere along with the decreasing air density dramatically increases their amplitude. This increase often leads to nonlinear wave breaking accompanied by energy release that produces temperature anomalies and sometimes reverses the direction of the zonal wind. The zonal wind in turn affects the wave propagation by modifying the wave refraction index.

Another wave that defines the earth's dynamics is the "Kelvin wave", which 
propagates in the ocean or atmosphere and balances the Earth's Coriolis force against a topographic boundary such as a coastline, or a waveguide such as the equator. For an observer traveling with the wave, the coastal boundary is always to the right in the Northern Hemisphere and to the left in the Southern Hemisphere. Hence the Kelvin waves move equatorward with the negative phase speed on a western boundary of the Pacific Ocean and poleward with the positive phase speed on an eastern boundary of the ocean; the waves move cyclonically around an ocean basin (Gill, 1982).

An example of thermodynamically generated pattern is COWL (Cold Ocean Warm Land) pattern. Wallace et al. (1996) argued that the COWL is essentially induced by the land-sea temperature distribution. Wallace et al. (1995) showed that the contrast in thermal inertia between land and ocean is responsible for the existence of the COWL pattern. The land surfaces, with their small heat capacities, equilibrate much more rapidly with the temperature of the overlying air mass than does sea surface temperature and thus experience larger temperature variability in response to month-to-month changes in atmospheric circulation patterns. It follows that hemispheric mean surface air temperature is largely determined by the temperature of the continents, even when surface air temperature over the oceans is taken into account in the averaging. By allowing the atmosphere to respond to ocean mixed layer temperature fluctuations only via heat exchanges directly aloft i.e. excluding the air-sea interaction in the coupled land-ocean model, Broccoli et al. (1998) have found that the coupling between atmospheric and oceanic circulations does not play a critical role in existence of this pattern.

\section{A Short Introduction of the Major Climate Patterns}

Now we briefly describe some major climate patterns formed in the Earth climate system. In view of many years of investigations and numerous publications, each of the patterns listed below deserves an extensive review so that this presentation could not be considered in any way as to complete and up to date.

\subsection{ENSO Pattern}

El Niño and La Niña are the warm and cool phases of a recurring climate pattern across the tropical Pacific called El Niño-Southern Oscillation, or ENSO (Figure 1). The pattern can shift the phase back and forth irregularly on the time scale of two to seven years, and each phase shift triggers changes of sea surface temperature (SST), air temperature, precipitation, and winds. These changes disrupt the large-scale air movements in the tropics, triggering a cascade of global side effects. The first written record of the impacts of El Niño was made in 1525 when the Spanish conquistador Francisco Pizarro observed rainfall occurring in the Peru deserts. Walker (Walker, 1928; Walker \& Bliss, 1932), who found a connection between barometer records on the East and West Pacific (between Tahiti and Darwin) and its variability, called this pattern "the Southern Oscillation." 
NOAA Extended SST

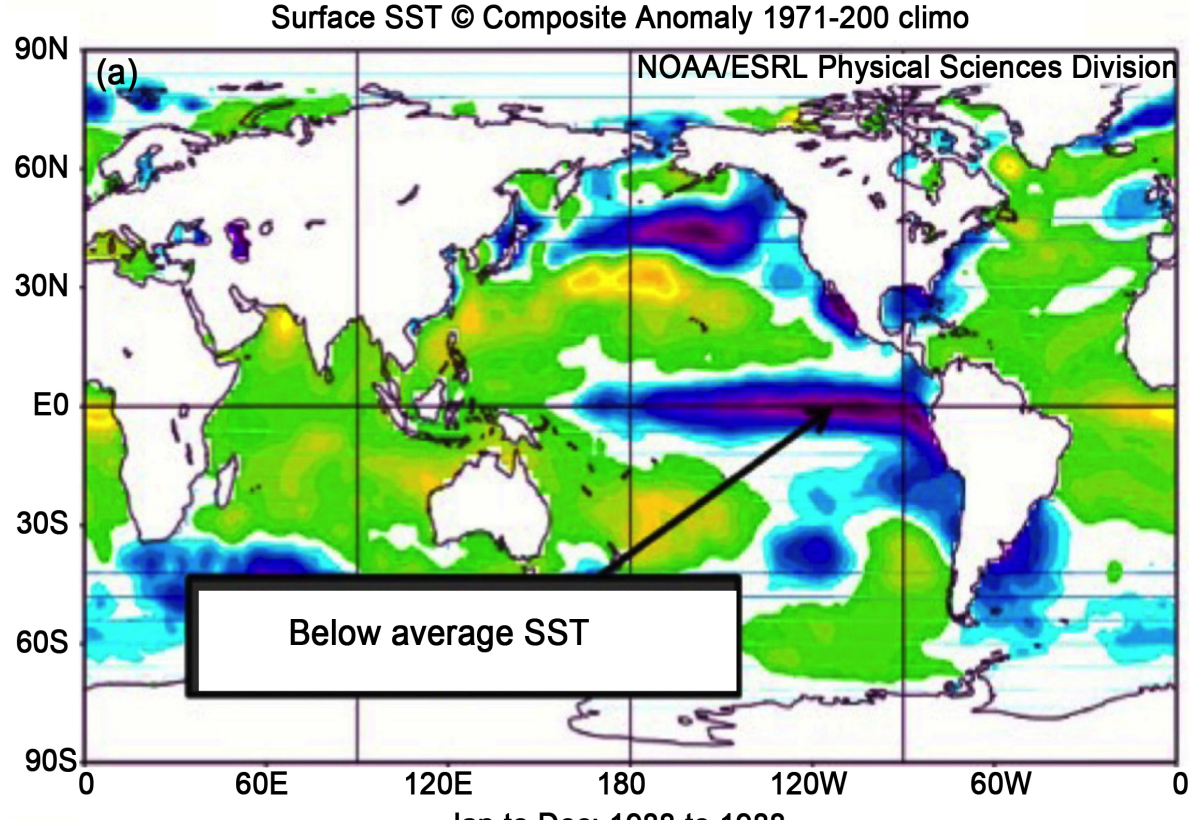

Jan to Dec: 1988 to 1988

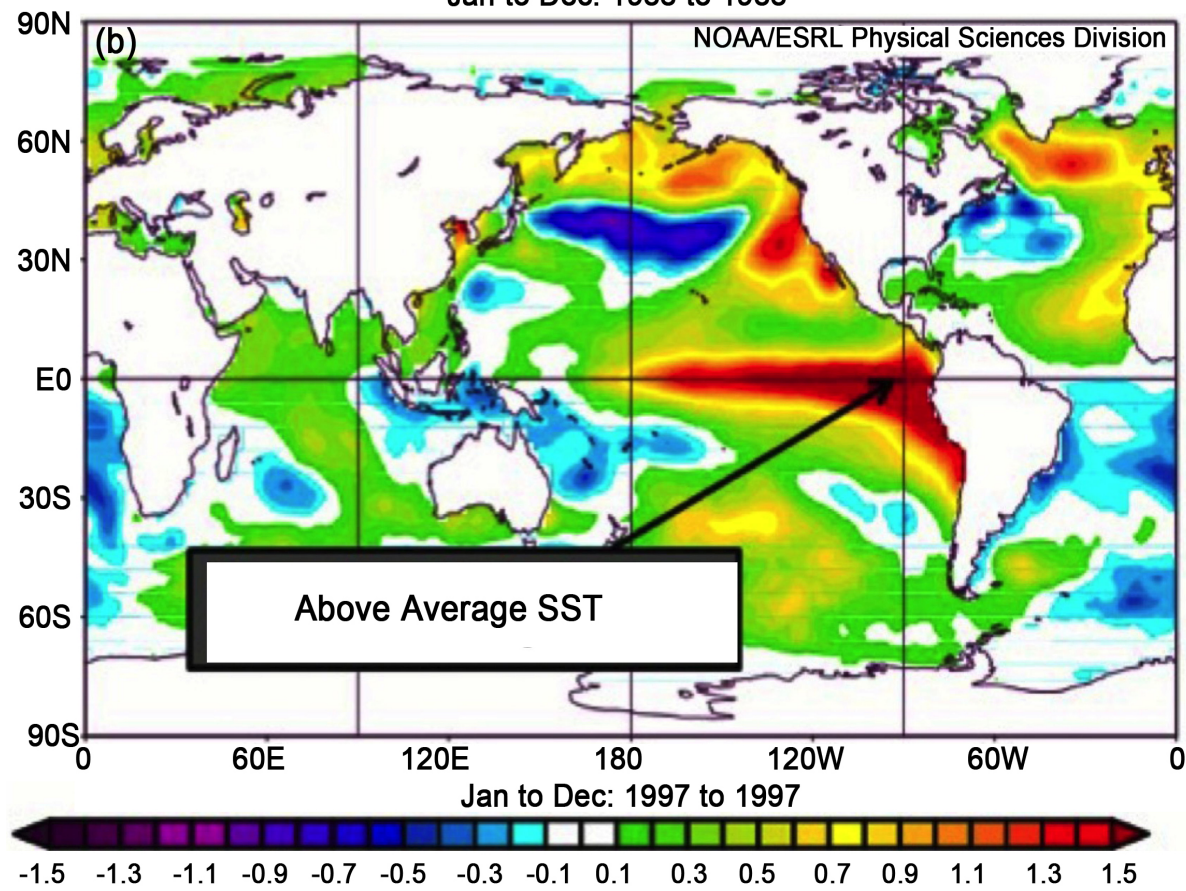

Figure 1. NOAA/ESRL Sea Surface Temperature (SST) anomaly based on 1971-2000 climatology: (a) 1988 La Niña condition; (b) 1997 winter El Niño condition.

Bjerknes (1969) noticed that the default state of the sea surface temperatures at the East Pacific is remarkably cold for such low latitudes. Since the western Pacific is relatively warm, a large SST gradient exists along the equatorial Pacific. As a result, there is direct thermal circulation in the atmosphere along the Pacific. The cool dry air above the cold eastern equatorial Pacific waters flows westward along the surface toward the warm West Pacific. There, the air is heated 
and supplied with moisture from the warm water. This systematic equatorial circulation associated with the zonal pressure gradient was named the "Walker Circulation" by Bjerknes. Bjerknes thought that fluctuations in this circulation initiated pulses in the Southern Oscillation and ultimately led to an ENSO event.

Bjerknes $(1966,1969)$ associated the feedback loop of the oceanic and atmospheric circulation over the tropical Pacific as a "chain reaction", noting that "an intensifying Walker Circulation also provides for an increase of east-west temperature contrast that is the cause of the Walker Circulation in the first place." Bjerknes also found that this interaction could operate in the opposite: a decrease in the equatorial easterlies diminishes the supply of upwelling cold water and the lessened east-west temperature gradient causes the Walker Circulation to slow down. He thus provided an explanation for the association of the low phase of the Southern Oscillation with El Niño as well as the association of the high phase with normal cold state of the Eastern Pacific.

Vecchi et al. (2006) explored changes in the Walker circulation since the midnineteenth century using observations and global climate model experiments. Observed Indo-Pacific sea-level pressure reveals a weakening of the Walker circulation. The size of this trend is consistent with theoretical predictions, is accurately reproduced by climate model simulations and within the climate models, is largely due to anthropogenic forcing. The climate models indicate that the weakened surface winds have altered the thermal structure and circulation of the tropical Pacific Ocean. In contrast, Sohn et al. (2013), who examined the changes in Walker circulation over the recent decades analyzing the sea surface temperature (SST), deep convective activities, upper-tropospheric moistening, sea level pressure (SLP), and effective wind in the boundary layer over the 30-year period of 1979008 showed that the eastern tropical Pacific has undergone cooling while the western Pacific has undergone warming over the past three decades, causing an increase in the SST gradient. Since the SST trend was attributed to more frequent occurrences of central Pacific-type El Niño in recent decades, it is suggested that the decadal variation of El Niño caused the intensified Walker circulation over the past 30 years.

A comprehensive review of current understanding of the spatio-temporal complexity of this climate cluster mode and its influence on the Earth system has been given by Timmermann et al. (2018). It has been shown that the leading Empirical Orthogonal Function (EOF), which usually displayed as the classical El Niño pattern with eastern tropical Pacific warming tongue, exhibits variability on quasi-quadrennial timescales ( 3 years). But the second EOF has enhanced variance on quasi-biennial and decadal timescales. The interplay of these two EOFs largely captures the spatial diversity of the observed ENSO mode. El Nio events can be viewed as the superposition of these two EOF modes, which results in a complexity of ENSO variability. On the other hand, La Nia events are weaker than El Nio events and exhibit less diversity in their spatial patterns, pointing to an asymmetry in the underlying dynamical processes for ENSO. 
The oscillatory nature of ENSO requires mechanisms that include both positive and negative ocean-atmosphere feedbacks. As nicely reviewed by Wang (2001), the delayed oscillator, the western Pacific oscillator, the recharge-discharge oscillator (Jin, 1997; Timmermann et al., 2018) and the advective-reflective oscillator (Picaut et al., 1997) have been proposed to interpret the oscillatory nature of ENSO. All of these oscillator models have a positive ocean-atmosphere feedback in the equatorial eastern and central Pacific hypothesized by Bjerknes (1969). Each, however, has different negative feedbacks that turn the warm (cold) phase into the cold (warm) phase. In the delayed oscillator, free Rossby waves generated in the equatorial Eastern Pacific propagate westward and reflect from the western boundary as Kelvin waves. Since thermocline depth anomalies for the returning Kelvin waves have signs opposite to those in the equatorial eastern Pacific, these anomalies provide negative feedback for the coupled ocean-atmosphere system to oscillate. In the Western Pacific oscillator, equatorial easterly wind anomalies in the Western Pacific, which are produced by Western Pacific off-equatorial cold SST and high SLP anomalies, induce an ocean upwelling response that evolves eastward along the equator to provide negative feedback. In the recharge-discharge oscillator, equatorial wind anomalies in the central Pacific induce the meridional Sverdrup transport that recharges (or discharges) equatorial heat content. It is the recharge-discharge process that leaves an anomalously deep (or shallow) equatorial thermocline that serves as the phase transition for the coupled ocean-atmosphere system. The advective-reflective oscillator assumes that anomalous zonal currents associated with wave reflection at the ocean boundaries and mean zonal current tend to stop the growth of El Niño. The unified oscillator model, Equation (2) includes all of the physics (Wang, 2001):

$$
\begin{gathered}
\frac{\partial T}{\partial t}=a \tau_{1}-b_{1} \tau_{1}(t-\eta)+b_{2} \tau_{2}(t-\delta)-\varepsilon T^{3} \\
\frac{\partial h}{\partial t}=-c \tau_{1}(t-\lambda)-R_{h} h \\
\frac{\partial \tau_{1}}{\partial t}=d T-R_{\tau_{1}} \\
\frac{\partial \tau_{2}}{\partial t}=e h-R_{\tau_{2}}
\end{gathered}
$$

where $T$ is the SST anomaly, $h$ is the thermocline anomaly, $\tau_{1}$ and $\tau_{2}$ are zonal wind stress anomalies. The parameters $a, b_{1}, b_{2}, c, d, e$ are constants, the parameters $\eta, \delta$ and $\lambda$ represent the delay times, and the parameters $E, R_{h}, R_{\tau_{1}}$ and $R_{\tau_{2}}$ are damping coefficients.

Ruzmaikin (1999) suggested considering ENSO as a stochastic driver that excites the atmospheric anomaly states (Figure 2). This idea led to a concept to make 11-year solar activity forcing of climate feasible through stochastic resonance-a mechanism that amplifies a weak input to a nonlinear bistable system by the assistance of noise (Gammaitoni et al., 1998). 

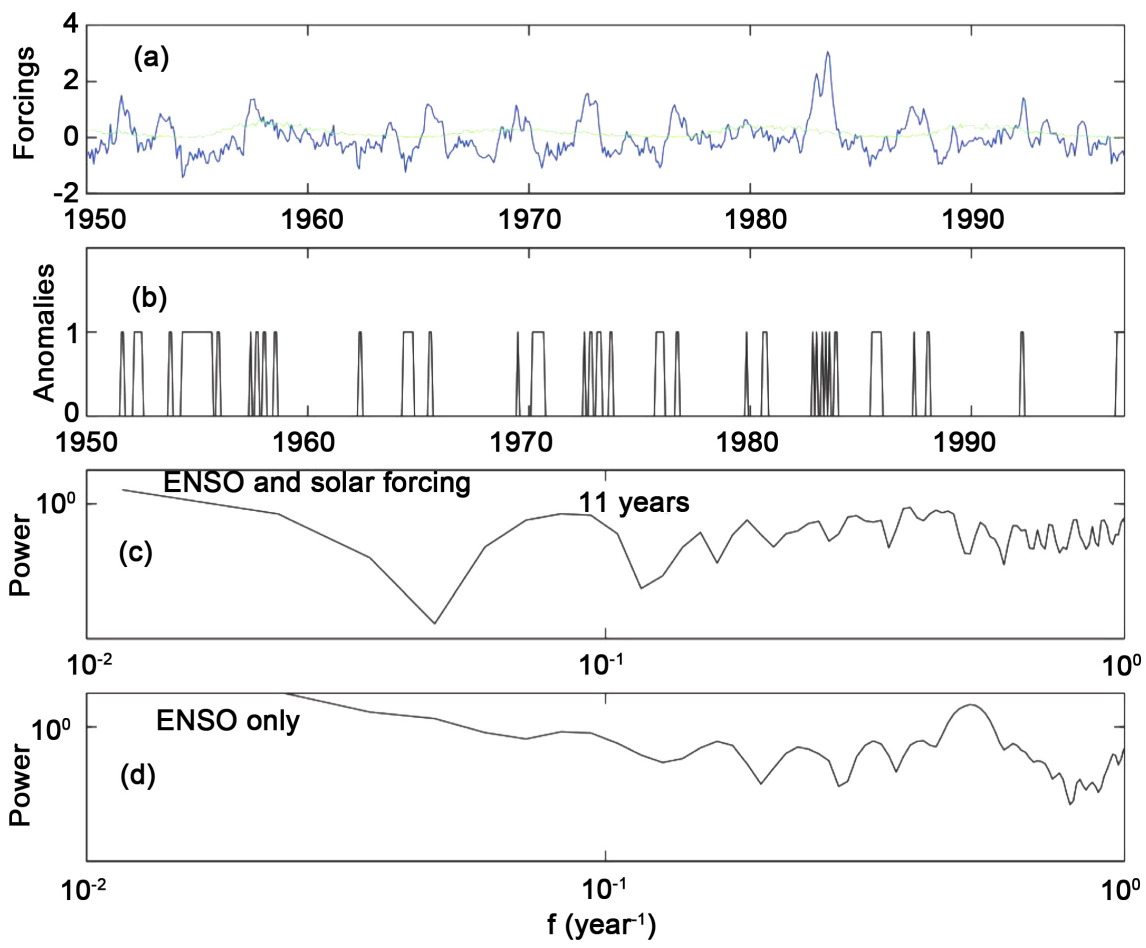

Figure 2. (a) 47-year long time series of observed Nino 3.4 index (blue line) and solar activity approximated by the sunspots number (green line); (b) The rectangular bars show when the system is in the anomalous state, the horizontal width of a bar gives a residence time in this state. Both the ENSO and sub-threshold solar forcing are included; (c) Spectrum of the function shown in the second panel; (d) Spectrum when only the ENSO forcing is present (Ruzmaikin, 1999).

\subsection{The Climate Pattern Generated by Sea-Land Thermal Contrast (COWL)}

One of the dominant modes of natural variability in the Northern Hemisphere is called the "Cold Ocean-Warm Land" (COWL) pattern. The COWL pattern was identified by partitioning the observed winter season time series of monthly mean surface air temperature into a very slowly varying radiative component, and a component exhibiting rapid year-to-year fluctuations, the latter comprising the COWL pattern (Wallace et al., 1995, 1996; Quadrelli \& Wallace, 2004), Figure 3. Broccoli et al. (1998) demonstrated that the COWL pattern appears to be a robust feature that can be extracted from both the observations and coupled model.

Wallace et al. (1996) pointed out that the COWL pattern does not appear as a single EOF of the $500 \mathrm{hPa}$ heights. Quadrelli and Wallace (2004) showed that the COWL pattern can be reconstructed as a linear combination of the first two EOFs of monthly mean December-March sea level pressure. Using the Northern Hemisphere land station data, it was determined that roughly half of the temporal variance of monthly mean hemispheric mean anomalies in surface air temperature during the period 1900-1990 were linearly related to the amplitude of a distinctive spatial pattern in which the oceans are anomalously cold and the 


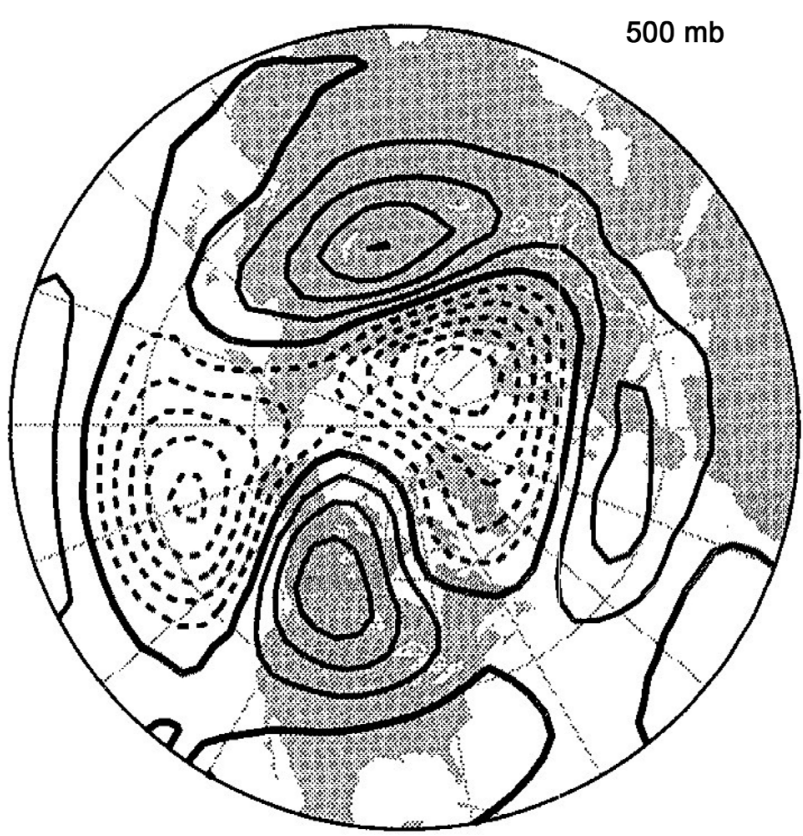

Figure 3. (a) The COWL pattern obtained by regression of the monthly mean geopotential heights at $500 \mathrm{hPa}$ upon hemispheric-mean surface temperature anomalies for cold season months in 1946-1993 (Wallace et al., 1996).

continents are anomalously warm poleward of $40^{\circ} \mathrm{N}$. Apart from an upward trend since 1975, to which El Niño has contributed, the amplitude time series associated with this pattern resembles seasonally dependent white noise. It is argued that the variability associated with this pattern is dynamically/thermodynamically induced and is not necessarily an integral part of the fingerprint of global warming (Wallace et al., 1995).

The internally generated variability in the COWL pattern identified in the coupled model integration was used to assess the importance of the upward trend in the amplitude of the observed structure-function over the last 25 years. This trend, which has contributed to the accelerated anthropogenic warming of Northern Hemisphere temperature over recent decades, may not be purely random (Broccoli et al., 1998).

\subsection{Annular Patterns (NAM and SAM)}

The planetary wave-zonal wind interaction of the atmospheric dynamics generates the major climate patterns in the middle-high latitudes called annular modes (http://www.atmos.colostate.edu). There are two annular modes: the Northern Annular Mode (NAM) and the Southern Annular Mode (SAM), Figure 4. These modes are characterized by north-south shifts in atmospheric mass between the polar regions and the middle latitudes and explain more of the week-to-week, month-to-month, and year-to-year variance in the extratropical atmospheric flow than any other climate phenomenon. For example, the NAM and SAM explain on the order of $20 \%-30 \%$ of the total variance of geopotential heights 


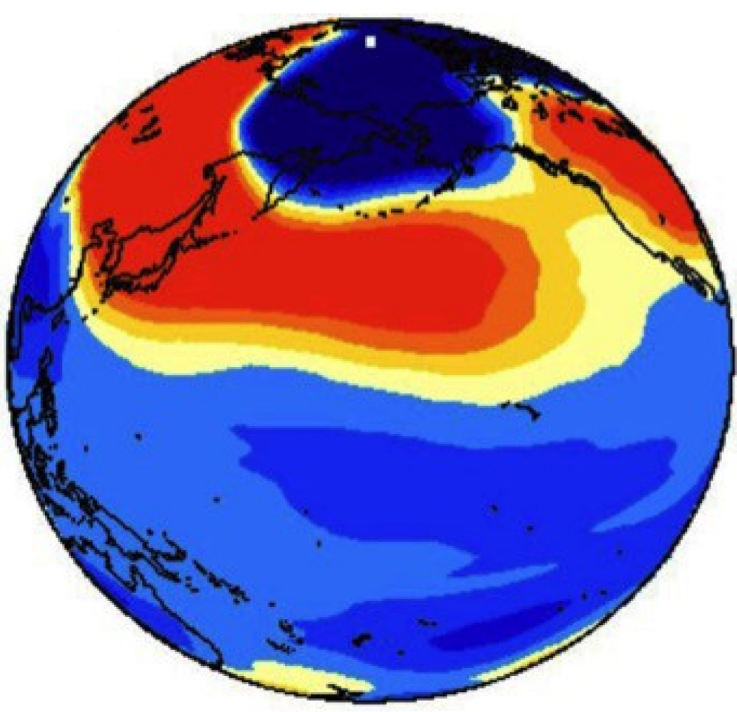

(a)

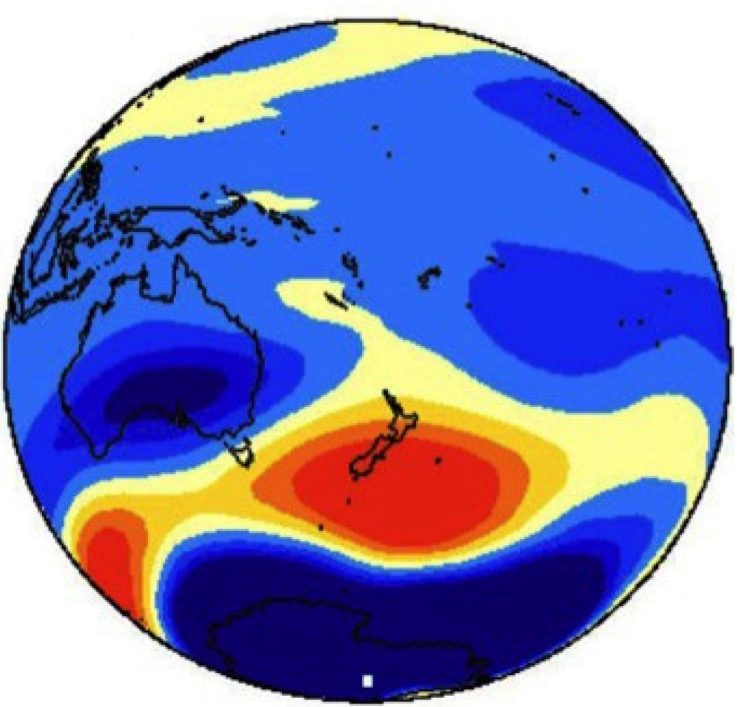

(b)

Figure 4. The NAM and SAM ring-like patterns of wintertime climate anomalies. A positive NAM at high latitudes manifests in low pressure and temperature, and strong wind; at low latitudes it is seen in high pressure and temperature, and weak wind. The signs of the anomalies are opposite for the negative NAM. Similar pattern is displayed by the SAM. For more details see the website of David Thompson at http://www.atmos.colostate.edu.

and wind fields of their respective hemispheres, depending on the level and timescale (Thompson \& Wallace, 1998).

The time series associated with annular modes are possibly consistent with a normally distributed red-noise process. The indices of the annular modes are based on the leading principal component (PC) time series of gridded geopotential height anomalies at a given pressure level. Thus the variability in the NAM is 
represented by its first principal component, called "the NAM index", which has noticeable magnitude mainly during the winter season (December to March or often October to March). The PC can be positive or negative thus indicating two phase states of the NAM and SAM. Thompson \& Wallace (2001) found a significant difference in cold weather events in diverse regions (such as minimum winter temperatures in Chicago, Paris and Tokyo) dependent on the sign of the NAM index.

It was suggested and demonstrated in numerical simulations that the excitation of the first EOF (i.e. the NAM), which characterizes the zonally-symmetric anomaly of atmospheric circulation, involves interaction between the planetary waves and the zonal-mean flow in the atmosphere (Limpasuvan \& Hartmann, 2000). The second EOF (PNA-type patern) reflects the non-zonally symmetric structure of the planetary waves (Quadrelli \& Wallace, 2004).

The nonlinear wave-zonal flow interaction (Holton \& Mass, 1976) can be envisioned as a dynamical system with two basic states in its phase space corresponding to positive (negative) anomalies (Chao, 1985; Yoden, 1987; Ruzmaikin et al., 2003, 2006a) i.e. positive (negative) NAM. The system spends some time in residence at one or another state wandering between the two states (Ruzmaikin et al., 2003, 2006a).

Thompson and Wallace (1998) noted that the strengthening of the polar vortex over the 30 years (1960-1990), unrelated to any known tropospheric forcing, has led to speculation that anthropogenically induced temperature changes at stratospheric levels might somehow be responsible. However the analysis of the residence time distributions for the Northern Annular Mode shows that the large difference of the tails of the residence time distributions for positive and negative phases of the NAM (characterized by the kurtoses) points to a temporal dominance of one of the phases in rarely occurring events (Ruzmaikin, 2009). This suggests an unrelated to the global warming explanation of the dominance of the positive NAM in mid-1960s to the late 1990s indicated by Thompson and Wallace (1998).

It has been shown that the NAM index at different heights of the atmosphere is statistically significantly affected by the solar variability (proxied by solar 10.7 cm flux, Figure 5) (Ruzmaikin \& Feynman, 2002). The effect varies depending on the time in the winter and the direction of the tropical stratospheric winds (the QBO), see Figure 5. Response of the stratosphere to solar variability, in particular at $30 \mathrm{hPa}$, and dependence of this response on the $\mathrm{QBO}$ phase was first discovered by Karen Labitzke (Labitzke, 1987) and further investigated by Labitzke and van Loon (For summary of their results see Labitzke (2004).) The most interesting extra finding by Ruzmaikin and Feynman (2002) was that at the beginning of winter at the West phase of the $\mathrm{QBO}$ and at the end of winter at the East phase of the QBO the atmosphere responds to solar activity in a coherent manner stretching from sea level to the top of the stratosphere, thus outlining a vertical extension of the NAM pattern. For comparison, we indicate the effect of 
(a) West QBO
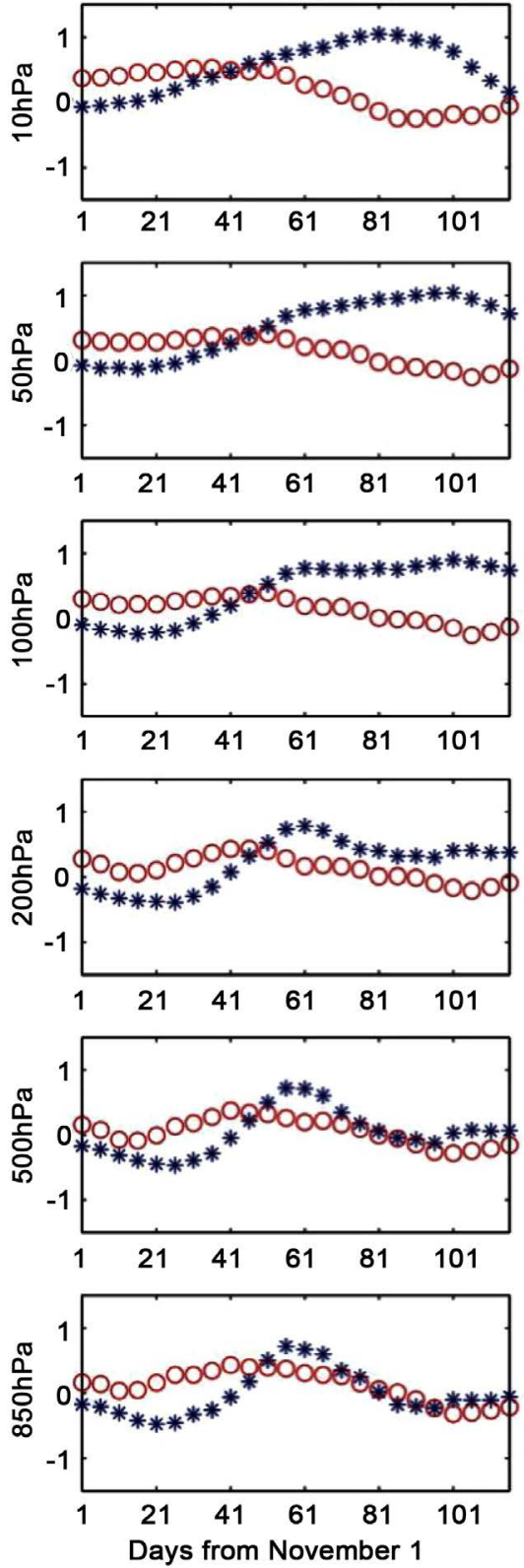

(b) East QBO
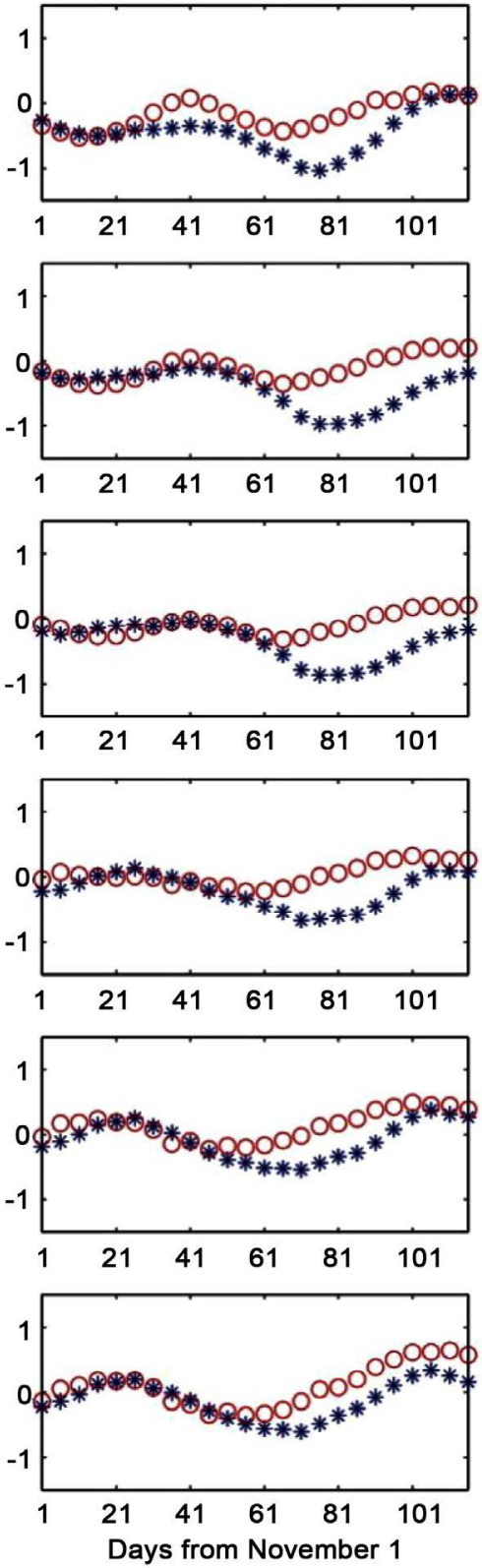

Figure 5. The solar variability influence on the NAM in the winter (November to March). The red circles mark the NAM index (the principal component of the first EOF of geopotential heights) for the high solar flux input on the Earth's stratosphere, the blue stars mark the NAM index for the low solar flux. The solar flux is proxied by the $10.7 \mathrm{~cm}$ solar radio flux. The case (a) corresponds to the West QBO, the case (b) corresponds to the East QBO. The effect is visible from the middle stratosphere $(10 \mathrm{hPa})$ to the troposphere $(850 \mathrm{hPa})$ (Ruzmaikin \& Feynman, 2002).

solar variability on the PNA index (see the next section). Note that although the PNA is close to the second EOF it is still a linear combination of the two EOFs (a reduced first and a strong second EOF). The change in the probability of having long residence times (i.e. effect on the tail of distribution) under external forcing is larger than the change in the mean residence time. As an example, we examine 
the solar variability forcing on the NAM. We show that the stochastic process that drives the NAM is affected by solar variability (Ruzmaikin \& Feynman, 2002). At high solar activity, the NAM spends slightly more time in its negative phase in the stratosphere and slightly less time (compare to the positive phase) in the troposphere. A particularly noticeable change in the tails of the distributions is seen near the tropopause. This difference should be taken into account in studying the role of solar variability on the stratosphere-troposphere coupling. Much stronger influence on the NAM may occur during rare but prolonged changes in solar activity. An example is the dominance of the negative NAM during the 70 -year-long Maunder Minimum of solar activity as inferred by Ruzmaikin et al. (2004b).

The effect of solar variability on the NAM is more pronounced on time scales longer than the 11-year solar cycle due to the thermal inertia of the oceans (Ruzmaikin et al., 2004b). Empirical studies show that solar variability influences North African climate on multi-decadal time scales (Stager et al., 2007; Ruzmaikin et al., 2006b). For example, using annual records of the water level of the Nile collected in 622 - 1470 A.D. two characteristic time scales that may be linked to solar variability were identified: a period of about 88 years and a period just exceeding 200 years (Ruzmaikin et al., 2006b). These time scales are characteristic of the rate of auroras (caused by solar activity) that were recorded in the Northern Hemisphere at the same time interval (Feynman \& Fougere, 1984; Ruzmaikin et al., 2006b). Ruzmaikin et al. (2006b) suggested that a possible physical link between solar variability and the low-frequency variations of the Nile water level involves the influence of solar variability on the NAM and on its North Atlantic Ocean and Indian Ocean patterns that affect the rainfall over the sources of the Nile in Eastern Equatorial Africa.

It has also been shown that the reconstructed sensitivity of the sea level temperature to a longer-term (multi-century) solar forcing in the Northern Hemisphere is in very good agreement with the empirical temperature pattern corresponding to changes of the NAM Ruzmaikin et al. (2004b). The temperature pattern (cold in Europe-warm in Greenland) associated with this mode was dominant during the Maunder Minimum.

Time evolution of the annular spatial patterns can also be traced. Data analyses (Kodera, 1995; Baldwin \& Dunkerton, 1999) and modeling (Shindell et al., 1999; Gray et al., 2003) show that wind anomalies in the upper-middle stratosphere move poleward and downward during the winter. A greater fraction of stratospheric perturbations penetrates to the Earth's surface during solar maximum conditions than during solar minimum conditions (Hameed \& Lee, 2005). These anomalies are affected by the variable solar UV flux that impinges on ozone and temperature at the top of the stratosphere (Haigh, 1994). Through the thermal wind relationship, temperature changes induce a gradient in the zonal wind that influences propagation of planetary waves. Since the interaction of the zonal-mean wind and planetary waves is considered as a probable mechanism of 
the NAM generation the solar influence on this interaction may explain why the poleward-downward propagation of anomalies depends on the level of solar activity.

Daily and monthly resolution indices of the annular modes are available from the NOAA CPC. The data is available from 1958 to present for the Northern Annular Mode and from1979 to present for the Southern Annular Mode (https://www.cpc.ncep.noaa.gov/). The NAM/NAO Indices for the Northern Annular Mode/North Atlantic Oscillation are available back to the middle 1800s based on station data over the Atlantic sector. The most widely used index is based on surface data from Iceland and Portugal or the Azores. An excellent source for historical indices of the NAM is maintained by Jim Hurrell at: https://www.cgd.ucar.edu/cas/.

The SAM Indices for the SAM preceding the satellite era (that is preceding 1979) are based on very limited observations: there are only a handful of stations over the high latitudes of the $\mathrm{SH}$, and there are no continuous data records over Antarctica prior to 1958. There are three different SAM indices available for the period preceding 1979. All are generated on the basis of midlatitude stations and/or tree ring records: 1) Data provided by Gareth Marshall (British Antarctic Survey) at http://www.nerc-bas.ac.uk/icd/gjma/sam.html; 2) Tree ring based reconstructions of the annular modes that can be obtained from Martin Widmann at GKSS (m.widmann@bham.ac.uk) and Julie Jones at Univ. Sheffield (Julie.Jones@Sheffield.ac.uk); 3) Midlatitude station-based values of the SAM available from Martin Visbeck at the University of Kiel at http://www.ifm-geomar.de/SAM.

\subsection{Atlantic Multidecadal Oscillation (AMO) and Atlantic Meridional Over-Turning Circulation (AMOC)}

Atlantic Multidecadal Oscillation is a mode of variability of the North Atlantic Ocean covering a region from 0 to $80^{\circ} \mathrm{N}$ with $60-80$ years of SST variations (Figure 6).

A possible mechanism of the AMO is based on the about 150-year instrumental record of a quasi-periodicity of about 70 years, with a few distinct warmer phases between ca. 193020131965 and after 1995, and cool phases between 190020131930 and 196520131995 (van Oldenborgh, et al., 2009). In models, AMO-like variability is associated with small changes in the North Atlantic branch of the Thermohaline Circulation called Atlantic Meridional Overturning Circulation (AMOC). However, historical oceanic observations are not sufficient to associate the derived AMO index to present-day circulation anomalies. Models and observations indicate that changes in atmospheric circulation, which induce changes in clouds, atmospheric dust and surface heat flux, are largely responsible for the tropical portion of the AMO.

The pattern of the Atlantic meridional overturning circulation (AMOC) is defined by the zonally-integrated component of surface and deep currents in the 

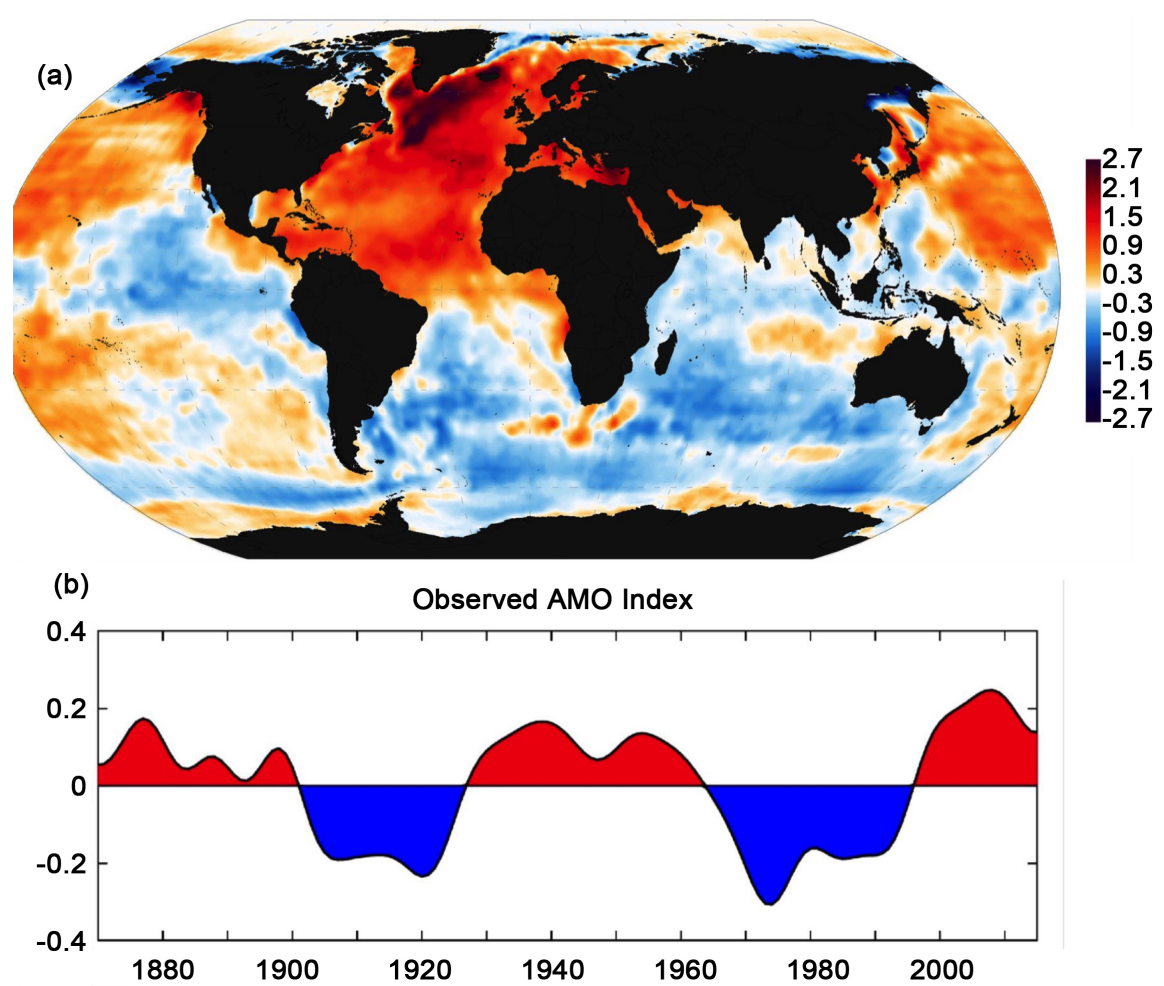

Figure 6. (a) AMO pattern extracted from SST monthly anomalies in 1870-2013, based on the record from Hadley Center. (b) AMO index for the same time period https://www.metoffice.gov.uk/weather/climate/.

Atlantic Ocean (Buckley \& Marshal, 2016). Weijer et al. (2019) presented a comprehensive review of the stability of the Atlantic Meridional Overturning Circulation based on concepts of the Dynamical Systems Theory, and conclude that it cannot be ruled out that the AMOC in the current climate is in, or close to, a regime of multiple equilibria. But there is considerable uncertainty in the location of stability thresholds with respect to our current climate state, there are no credible indications of where the present-day AMOC is located with respect to thresholds.

\subsection{Pacific North-American Pattern (PNA)}

PNA (Figure 7) had been identified as a pattern of the mid-tropospheric geopotential height field extending from the mid-Pacific to eastern North America (Wallace \& Gutzler, 1981). Long-sustained winter regimes of alternating high and low pressure in Greenland with effects on climate in Europe were found to be associated with the pattern of the long waves in the upper westerlies showing a general reversal over the Northern Hemisphere and winter climate variability along the Atlantic coast of North America (Dickson \& Namias, 1976). The positive phase of the PNA pattern is associated with above-average temperatures over western Canada and the extreme western United States, and below-average temperatures across the south-central and southeastern U.S.

The positive phase is also associated with an enhanced East Asian jet stream 
Pacific / North American Pattern Correlation with Surface Temperature Departures

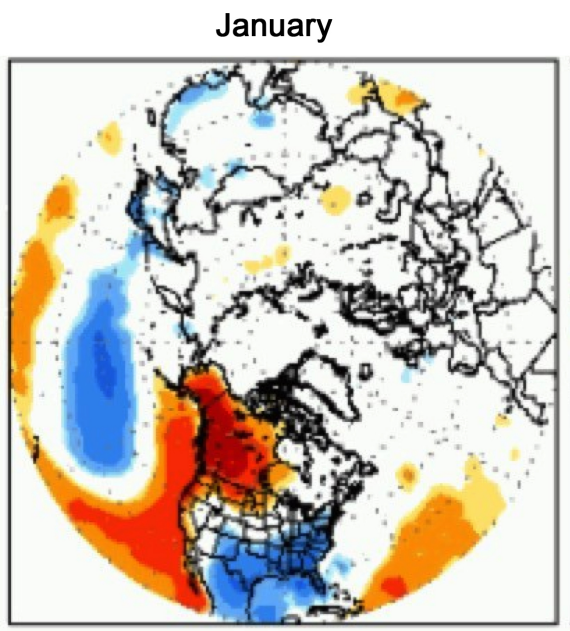

July
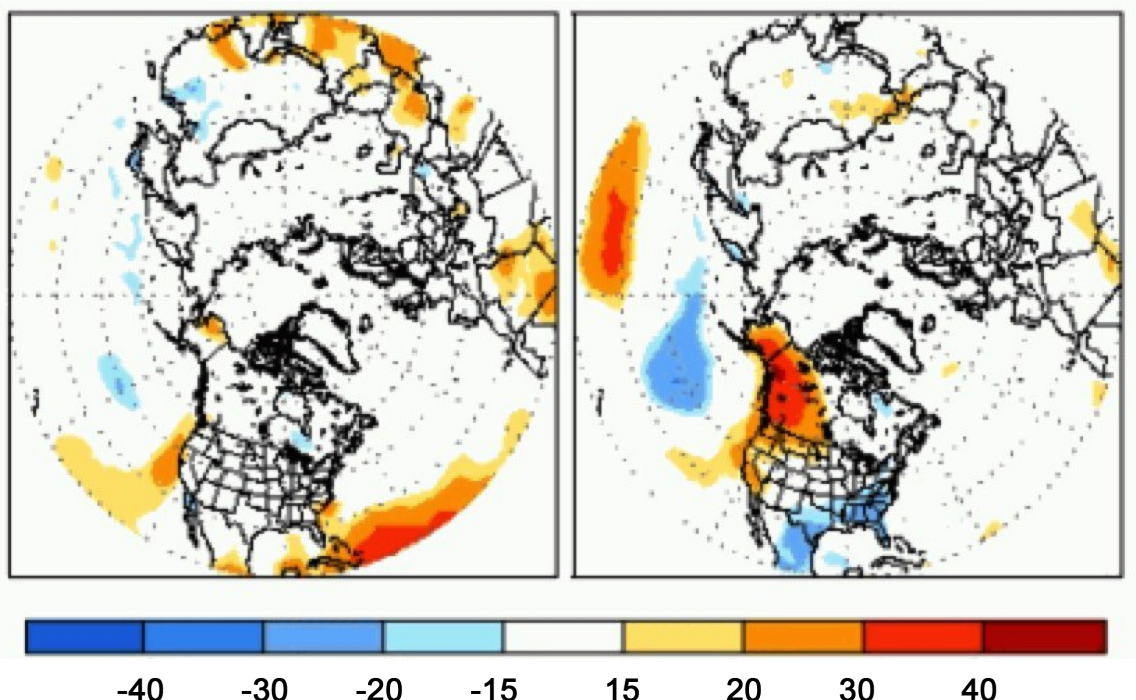

$-40$

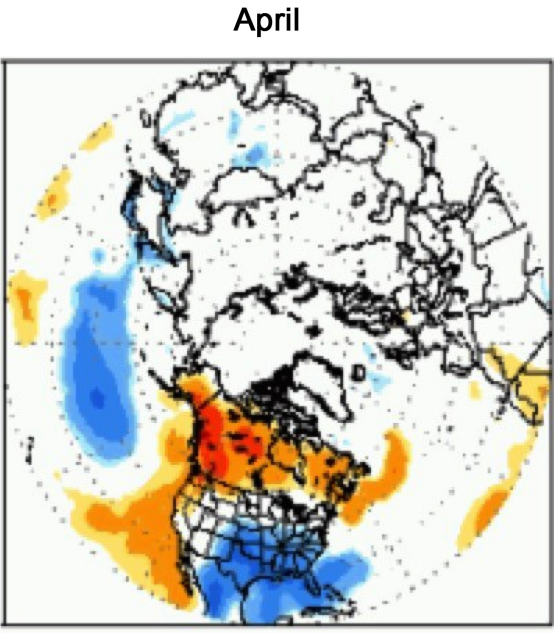

October

30
40

Figure 7. The PNA pattern for January, April, July, and October, displayed so that the plotted value at each grid point represents the temporal correlation between the monthly standardized geopotential height anomalies at that point and the teleconnection pattern time series valid for the specified month (NOAA Center for Weather and Climate Prediction).

and with an eastward shift in the jet exit region toward the western United States. The negative phase is associated with a westward retraction of that jet stream toward eastern Asia, blocking activity over the high latitudes of the North Pacific, and a strong split-flow configuration over the central North Pacific. The positive phase of the PNA pattern tends to be associated with El Niño, and the negative phase tends to be associated with La Niña.

The mechanisms that form and drive PNA pattern were extensively investigated by Dai et al. (2017). The main mechanism involves a poleward-propagating Rossby wave train that has been excited by tropical convection. It also involves 
barotropic amplification of a PNA-initiated disturbance due its interaction with the zonally asymmetric climatological flow. The mechanism includes amplification through a positive feedback onto the growing teleconnection pattern by high-frequency eddy vorticity fluxes.

The PNA is affected by long-term solar variability (Ruzmaikin, 2007). Figure 8 shows the projection of the Total Solar Irradiance (TSI) on the PNA pattern. The 21-century deep minimum of solar variability and the extended solar activity minima in the 19th and 20th centuries (1810-1830 and 1900-1920) are consistent with minima of the Centennial Gleissberg Cycle (CGC), a 90 - 100 year variation of the amplitude of the 11-year sunspot cycle observed on the Sun and at the Earth (Feynman \& Ruzmaikin, 2014). The Earth's climate response to these prolonged low solar radiation inputs involves heat transfer to the deep ocean causing a time lag longer than a decade. It had been found that the Pacific North American pattern (PNA) is a dominant spatial pattern of the climate response to CGC, which allows distinguishing the CGC forcing from other climate forcings (Ruzmaikin \& Feynman, 2015). The CGC minima, sometimes coincidently in combination with volcanic forcing, are associated with severe weather extremes. Thus the 19th-century CGC minimum coexisted with volcanic eruptions, led to
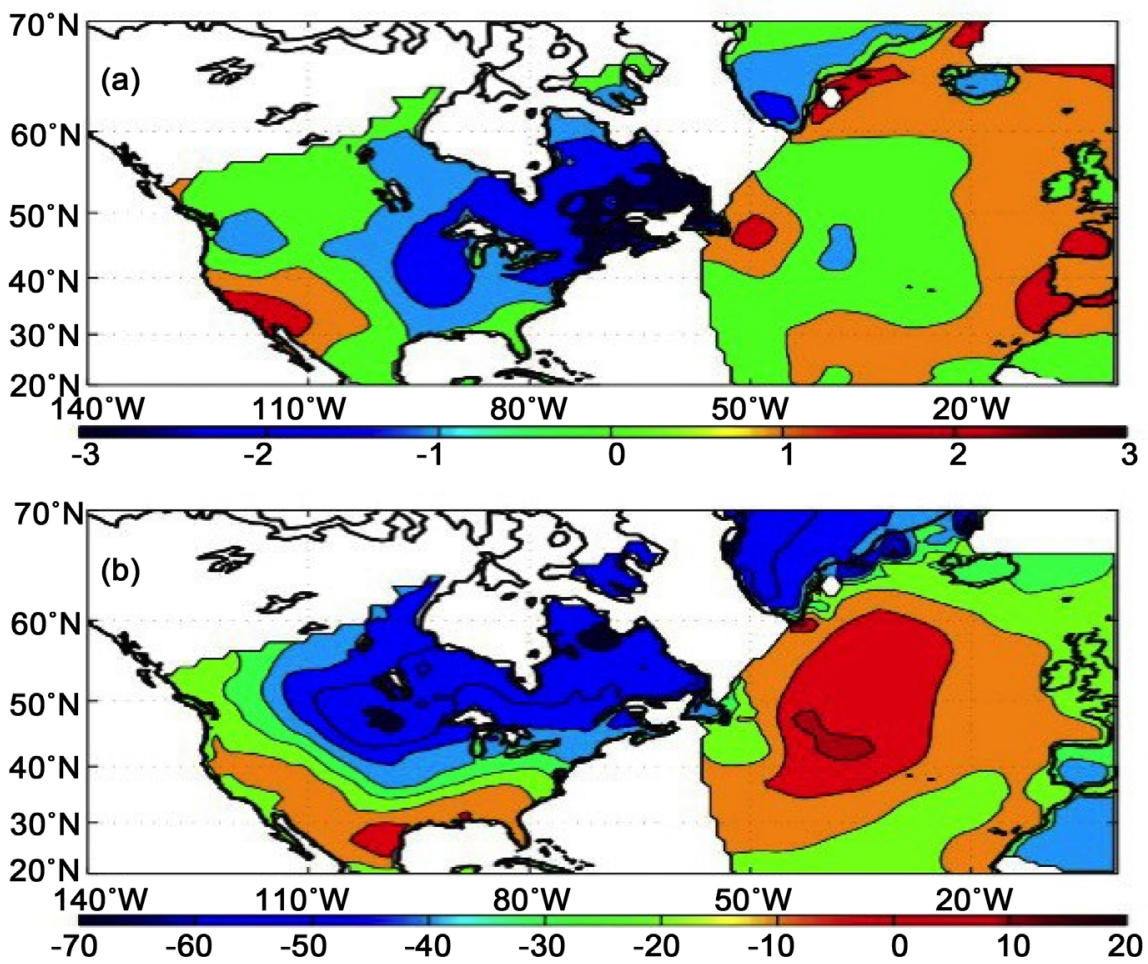

Figure 8. (a) Projections of the global (land plus ocean) temperature maps (PNA pattern) on the Total Solar Irradiance (TSI). The maps are constructed from the Berkeley Earth record (http://berkeleyearth.org/data/) for the time period 1850-1999. (b) The PNA pattern reconstructed by Trouet and Taylor (2009), see World Data Center for Paleoclimatology, https://www.ncdc.noaa.gov/). The characteristic features of the PNA pattern, such as the temperature anomaly of opposite signs over the USA, are seen in both images (Trouet \& Taylor, 2009). 
especially cold conditions in United States, Canada and Western Europe in 1816 called "year without summer" (c.f.

http://www.bellrock.org.uk/misc/miscyear.htm).

\subsection{Pacific Decadal Oscillation Pattern (PDO)}

The PDO was first introduced by Mantua et al. (1997) as the leading EOF of North Pacific $\left(20^{\circ} \mathrm{N}-70^{\circ} \mathrm{N}\right)$ monthly-averaged anomalies of Sea Surface Temperature (SST). The anomalies were defined as departures from the climatological annual cycle after removing the global mean SST (Figure 9). During a "positive" (warm), phase, the west Pacific becomes cooler and part of the eastern ocean warms; during a "cool" or "negative" phase, the opposite pattern occurs. Mantua and Hare (2002) described PDO as a long-lived El Niño-like pattern of Pacific climate variability, and by others as a blend of two sometimes independent modes having distinct spatial and temporal characteristics of North Pacific sea surface temperature variability. A growing body of evidence highlights a strong tendency for PDO impacts in the Southern Hemisphere, with surface climate anomalies over the mid-latitude South Pacific Ocean, Australia and South America. Interdecadal changes in Pacific climate have widespread impacts on natural systems, including water resources in the Americas and many marines

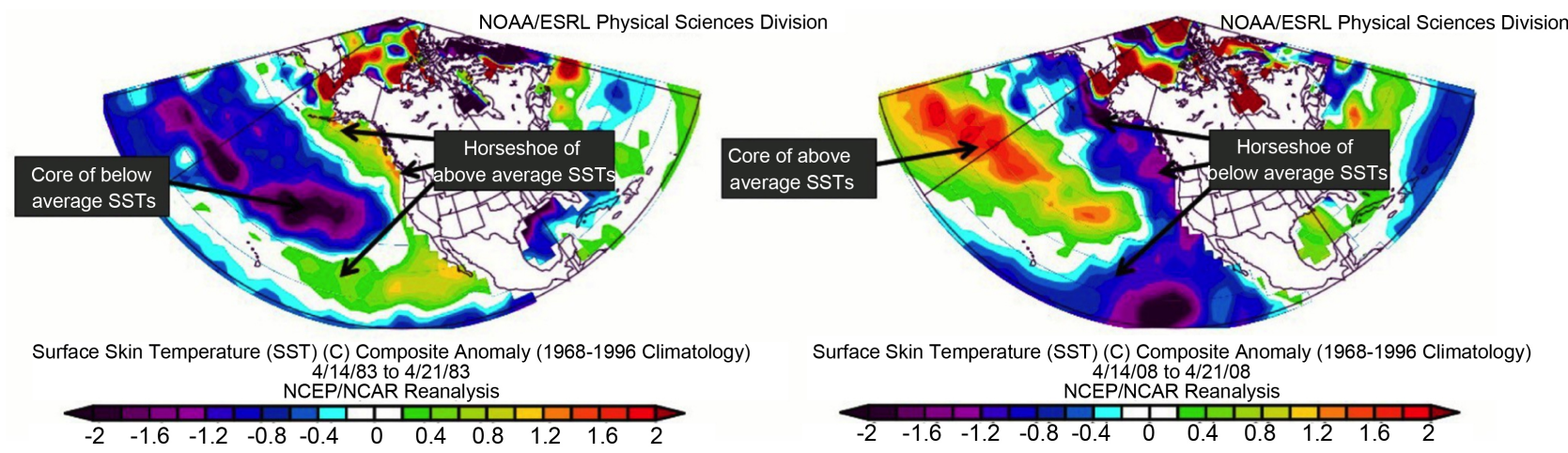

Monthly PDO Index: 1900 to 2009

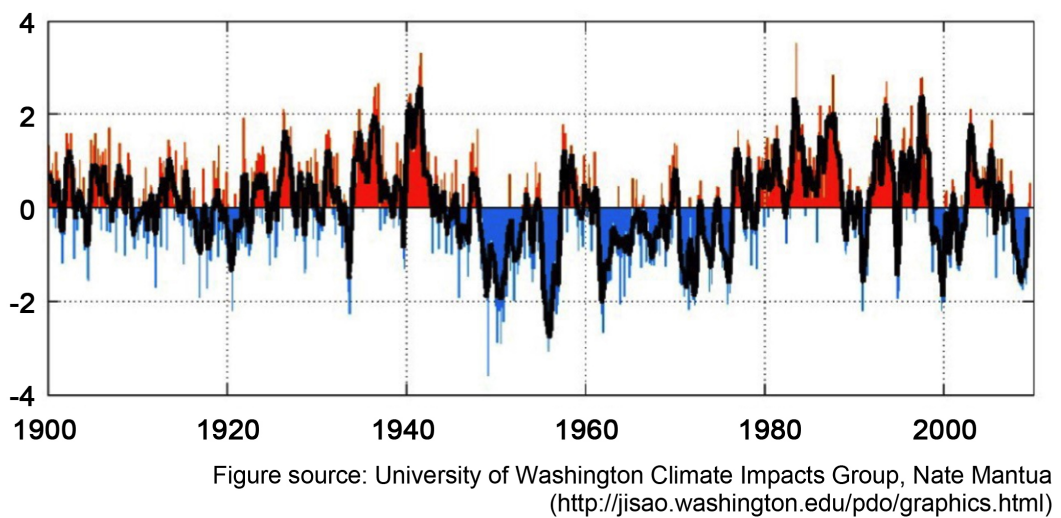

Figure 9. (a) Two phases of the PDO pattern extracted from SST monthly anomalies, based on NCEP/NCAR Reanalysis for 1900-2013. (b) PDO index for the same time period constructed by Nate Mantua (Mantua \& Hare, 2002). 
fisheries in the North Pacific. Tree-ring and Pacific coral-based climate reconstructions suggest that PDO variations-at a range of varying time scales-can be traced back to at least 1600, although there are important differences between different proxy reconstructions. The 20th Century PDO fluctuations were most energetic in two general periodicities-one from 15-to-25 years, and the other from 50 -to-70 years.

Related to PDO is the Interdecadal Pacific oscillation (IPO, Figure 10). IPO is an oceanographic/meteorological phenomenon similar to the Pacific decadal oscillation (PDO), but occurring in a wider area of the Pacific. While the PDO occurs in mid-latitudes of the Pacific Ocean in the northern hemisphere, the IPO stretches from the southern hemisphere into the northern hemisphere.

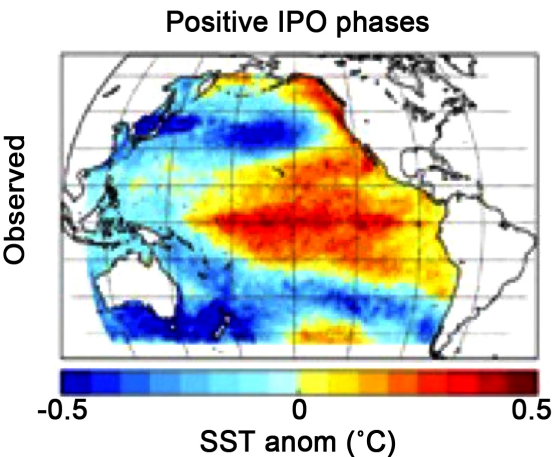

(a)

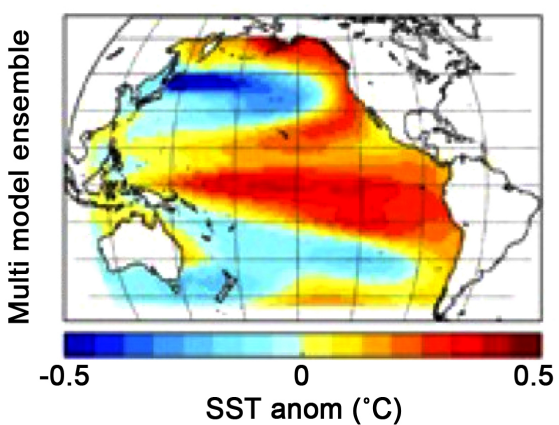

(c)

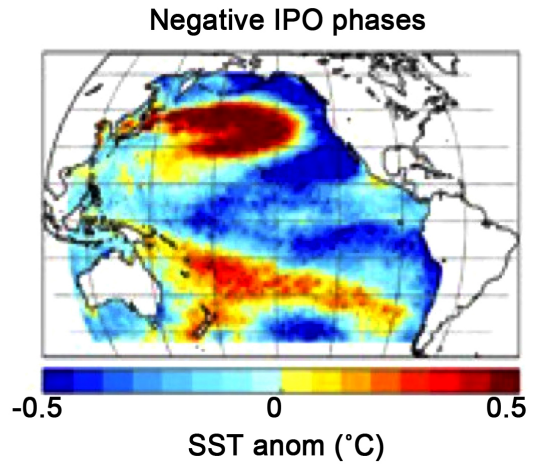

(b)

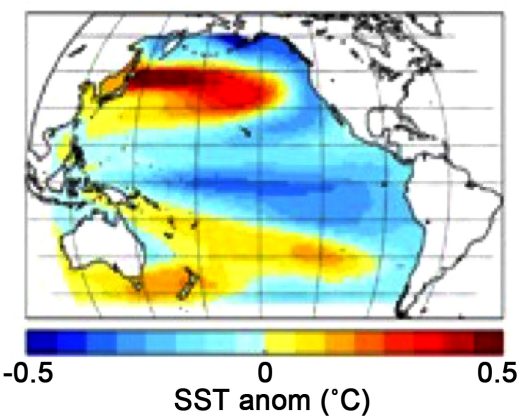

(d)

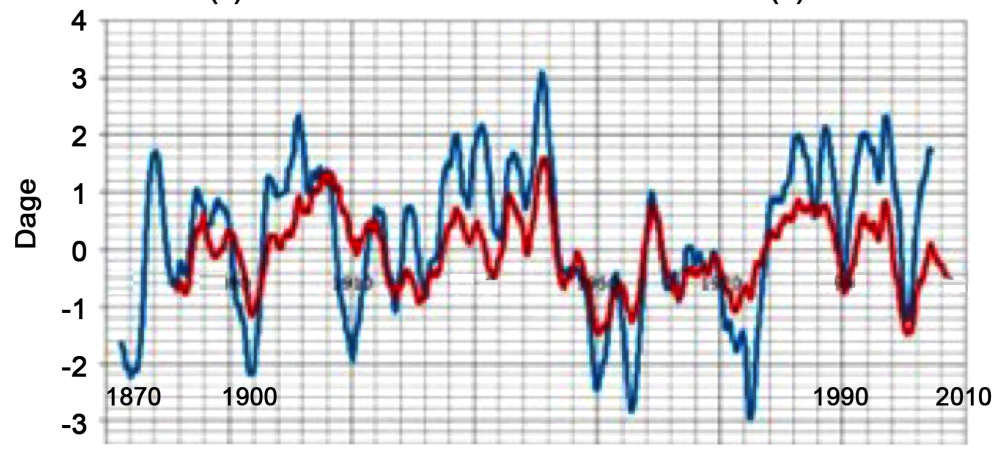

(e)

Figure 10. IPO patterns in models and observations (Henley et al., 2017). Observed IPO spatial patterns in ( $a, c)$ IPO positive and (b, d) IPO negative phases. (e) IPO from Jan 1871 to Sep 2005 (blue) and PDO from Jan 1880 to Feb 2008 (red) smoothed with 37-month filter (images are from the Hadley Center). 
The period of the IPO oscillation is roughly 15 - 30 years. Positive phases of the IPO are characterized by a warmer than average tropical Pacific and cooler than average northern Pacific. Negative phases are characterized by an inversion of this pattern, with cool tropics and warm northern regions. The IPO is considered as pattern of ENSO-like decadal variability, typically it has been defined as the projection of monthly Pacific SST data upon a pattern representing low-pass (decadal) global SST variability (Newman et al., 2016) driven by both interannual and decadal ENSO variability, which is coherent between the North and South Pacific. The North and South Pacific centers of action in the IPO regression pattern are roughly equivalent but the PDO North Pacific center is significantly enhanced.

Although earlier modeling suggested that the PDO might be a physical mode of coupled ocean-atmosphere interaction oscillating on decadal time scales, the later research (Newman et al., 2016) has found that the PDO is not a single physical mode of climate variability but instead represents the combination of different processes including random atmospheric forcing, teleconnections from the tropical Pacific, and ocean Rossby waves/shifts in the basin-wide ocean gyre circulation, which operate on different time scales. The random atmospheric forcing can be represented by a slow dynamical system integrating fast forcing approximated as white noise, and the ocean at a given location is treated as a motionless mixed layer in which surface heat fluxes both force and damp SST. The forcing is represented by fluxes associated with weather variations, which relative to oceanic time scales have approximately no memory and the same variance at all time scales (i.e. white noise). The resulting SSTA are damped by a linear negative air-sea feedback, representing loss (gain) of heat with the atmosphere from anomalously warm (cold) waters. Another forcing is the ENSO tropical Pacific SST anomaly, which induces tropical precipitation that shifts forcing global atmospheric teleconnections by altering near-surface air temperature, humidity, wind, and clouds far from the equatorial Pacific. When El Niño events peak during boreal winter, the Aleutian low deepens and the changes in the surface heat fluxes, wind-driven mixing, and Ekman transport in the upper ocean all act to create a positive PDO pattern.

\section{Discussion of Climate Role of the Patterns}

\subsection{Influence of Climate Patterns on the Global Trend}

Global warming experienced a pronounced hiatus during the period 1998-2013, which started from a very warm El Nino year 1998 (Trenberth \& Fasullo, 2013; Trenberth et al., 2014; IPCC, 2014). The global temperature trend dropped to $0.05 \mathrm{C} /$ decade compared with the previously recorded long-term trend $0.12 \mathrm{C} /$ decade. Paleoclimate records show that the decades of low global temperature trend were found not exceptional (IPCC, 2014).

Despite the continuous anthropogenic influence on climate in the form of the greenhouse release $\left(\mathrm{CO}_{2}\right.$ level now crossed a record high level of $400 \mathrm{ppm}$ in 
2013) a 15-year plateau in global mean temperature had not been predicted by most climate models. This plateau in global warming, or climate hiatus, is highly puzzling for the climate research community especially in view of record-high extreme weather events (coldest and hottest temperatures and floods). The problem is to identify the actual mechanism of climate variability that causes the hiatus. There could be two major potential causes: 1) The reduced input of solar irradiance onto the Earth system due to the deep minimum of solar activity (the so-called Gleissberg cycle minimum); and 2) The role of the heat absorption by the ocean including its deep layers.

The strongest pause in the rise in global mean surface temperatures is in the northern winter mainly of the central and eastern Pacific Ocean and over northern continents associated with the PDO in its negative phase Trenberth et al. (2014).

The COWL mode plays its role. At hiatus, the ocean uptakes the heat, i.e. stays cooler than land. This should intensify the COWL mode of land-ocean exchange. When during hiatus the COWL mode spends more time in its one phase, say cold ocean-warm land, the normal air exchange is broken and there are more extreme weather events (hot spots, floods) over land. Due to enhanced evaporation over wet places and lack of moisture supply to dry areas, this is what might happen in Europe. It apparently leads to the more intense formation of the Deep Convective Clouds (DCC) over land and suppressed DCC formation over oceans (Aumann \& Ruzmaikin, 2013).

The slowdown in the rate of global warming in the early 2000s is not evident in the model experiments due to ensemble average of natural climate variabilities (Meehl et al., 2014). However, as shown by these authors, a number of individual ensemble members from that set of models successfully simulate the early-2000s hiatus when the observed negative phase of the IPO occurred that contributed to the early-2000s hiatus. If the recent methodology of initialized decadal climate prediction could have been applied in the mid-1990s using the Coupled Model Intercomparison Project Phase 5 multi-models, both the negative phase of the IPO in the early 2000s as well as the hiatus could have been simulated, with the multi-model average performing better than most of the individual models. Kosaka and Xie (2013) showed that accounting for recent cooling in the eastern equatorial Pacific reconciles climate simulations and observations. They presented a method of uncovering mechanisms for global temperature change by prescribing, in addition to radiative forcing, the observed history of sea surface temperature over the central to eastern tropical Pacific in a climate model. Although the surface temperature prescription is limited to only 8.2 percent of the global surface, the model reproduces the annual-mean global temperature remarkably well with correlation coefficient $r=51$ for 1970012 (which includes the last hiatus and a period of accelerated global warming). The simulations capture major seasonal and regional characteristics of the hiatus, including the intensified Walker circulation, the winter cooling in northwestern of the North Ameri- 
$\mathrm{ca}$ and the prolonged drought in the southern USA. The results showed that the current hiatus is part of natural climate variability, tied specifically to a La Niña-like decadal cooling.

\subsection{Persistence of Climate Patterns}

Here we will assume that climate patterns can be treated as the attractors of general dynamical systems, to which the climate system does belong. The assumption that the climate patterns are the attractors of the climate dynamical system is justified by a number of previous researchers such as Corti, Palmer, Ghil and other authors referred in this paper. A simple representation of attractors is potential wells (Khatiwala et al., 2001; Ruzmaikin, 2009). Does external forcing change the spatial structure of patterns? The model studies of the Lorenz system and double-well dynamical systems show that the positions of the wells determining the localization of the climate patterns are changed only slightly. A model of the mean zonal flow-planetary wave interaction (Ruzmaikin et al., 2003) also indicates weak changes. Observational evidence of pattern change is limited so far but for example, Kodera (1995) found that during low solar activity the NAO pattern is confined to the Atlantic sector, while during the high solar activity the NAO-related anomalies extend over the whole Northern Hemisphere.

Introducing an external forcing would change either the phase states or the residence times (occupation frequencies) of the states. According to Rossby (1941), forcing does not change the states (i.e. the spatial structure of the climate patterns characterized by the EOFs) but only affects the mean residence times of the states. The Rossby conjecture was further advocated by Palmer (1999) and Corti et al. (1999). For visual illustration (Figure 11) Palmer presented a picture with two cups representing the phase states: a ball is randomly thrown from above for simulating occupation of the states, and a fan imitating the external force (Figure 10(a)). He also supported the hypothesis by using as an example the Lorenz dynamical system, which (for a certain range of parameters) has two basic states. However, further analysis of the forced Lorenz system (Khatiwala et al., 2001) showed that the change in the mean residence times is a small effect compared with a more dramatic change in the tail of the probability distribution of the residence times, meaning the increase in the frequency of occurrence of extremely persistent events. The main reason for this is that the Rossby-Palmer conjecture missed an extra and critical feature of this no-linear system: the energetic barrier $\Delta U$ separating the system (the ball) in one of the states from transition to the other state (Figure 10(b)) (Ruzmaikin, 2007). As known from the 20th-century studies, the residence time in a state is exponentially proportional to the height of the barrier (the Kramers formula (Kramers, 1940)). An external forcing affects the depth of a state thus effectively increasing (or decreasing) the barrier. And, due to the exponential sensitivity of the residence time, even a small change of the barrier may induce noticeable effect on the time spent in that state. A numerical study of a model double-well potential system 
with stochastic transitions between the wells showed that when one of the wells is made deeper (by changing a parameter in the potential) the probability distribution of residence times in this well displays a longer tail (Khatiwala et al., 2001).

\subsection{A Role of Patterns in the Long-Term Climate Prediction}

Ed Lorenz in his celebrated paper on chaos Lorenz (1963) wrote: "When our results concerning the instability of nonperiodic flow are applied to the atmosphere, which is ostensibly nonperiodic, they indicate that prediction of the sufficiently distant future is impossible by any method unless the present conditions are known exactly. In view of the inevitable inaccuracy and incompleteness of the weather observations, precise very-long-range forecasting would seem to be nonexistent". However, in response to this statement Bunimovich (2015) provided some surprising mathematical results suggesting that a long-term forecast in dynamical systems with complex behavior is not so hopeless. After rigorously proving a prediction theorem for a simple chaotic dynamical system, he shows that by collecting enough data it is possible in principle to uncover the hierarchy of states for chaotic dynamical systems. This finding indicates that combining an analysis of chaotic bursts (transitions through chaotic dynamics) between rather regular states of the atmosphere (like cyclones, anticyclones and other types of eddies) may improve a weather/climate forecast on long time scales.

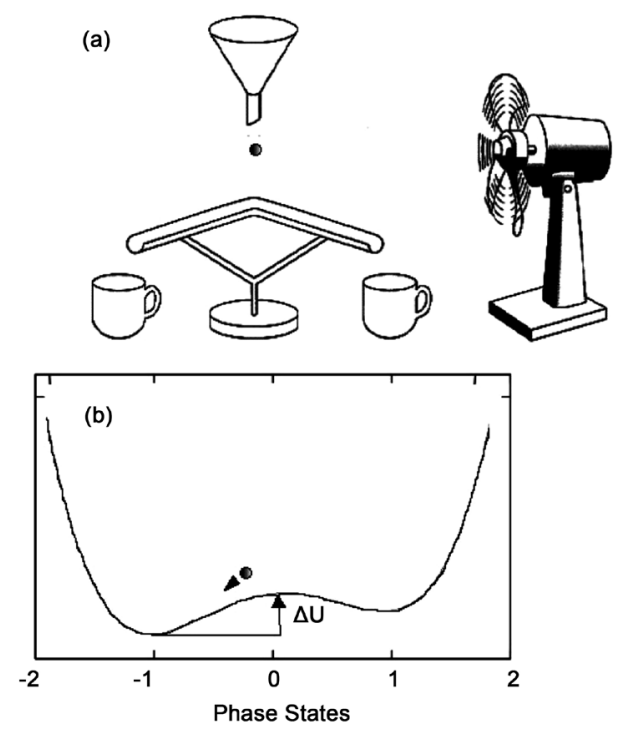

Figure 11. A pictorial illustration of possible mechanisms of external influence on a climate pattern: (a) As envisioned by Palmer (1999): Solid caps correspond to two states of the pattern. Random population of the cups is controlled by dropping a ball. Forcing is depicted as a fan, which tends to blow the ball toward the left-hand cup. (b) As suggested by Ruzmaikin (2007) (see also Khatiwala et al. (2001)): There is a barrier between the states. Random transitions from one state to another are controlled by internal Earth's dynamics. The external forcing (such as solar variability) slightly changes the depth of one of the potential wells for some time leading to an exponentially amplified increase of the residence time in that well and, as a consequence, a longer persistence of this state. 


\subsection{Time Patterns in Climate Structure}

Lovejoy (2013) argued that there are three qualitatively different regimes in the weather-climate system: The high-frequency regime is clearly the weather and the low-frequency regime is clearly "the climate", but there is also an in-between regime had been described with a spectral plateau as "low-frequency weather". It was dubbed "macroweather" because it is a kind of large-scale weather (not small-scale climate) regime. In each regime, the standard deviation is $S(\delta t) \approx \delta t^{H}$, so that the standard deviations of the fluctuations at "weather", "macroweather", and "climate" scales are roughly power laws (scaling) and are distinguished by their exponents. This finding generalizes the stochastic approach introduced by Hasselmann (1976) but still lucks of the role of spatial-temporal correlations that form the climate patterns.

\section{Conclusion}

After all the questions arise: 1) why should we be interested in climate patterns, and 2) is there a need to advantage the knowledge of them.

- It is well excepted that specific climate patterns, for example, El Niño or PDO, greatly influence the weather conditions not only locally but also over the globe.

- The climate patterns may substantially affect the global trend (see Section 5.1).

- External forcing of climate, such as solar forcing, can be well seen in climate patterns and may be deemed and difficult to record globally.

- Climate patterns allow prediction of long-term evolution of climate.

- To advance the knowledge of climate patterns it would be important to better understand the mechanisms of their formation.

- Use the arsenal of accumulated knowledge of dynamical systems that treat climate patterns as attractors of the Earth's dynamical system.

Currently, there are an extensive number of publications that include the weather effects of specific climate patterns, such as the ENSO, PDO and NAM. However, there is a gap in research and publications devoted to investigation of mechanisms of climate pattern formation and their role in climate prediction. This review is an attempt to fill this gap and stimulate research of climate patterns both from observational and modeling viewpoints.

\section{Acknowledgements}

This work was supported in part by the Jet Propulsion Laboratory of the California Institute of Technology, under a contract with the National Aeronautics and Space Administration.

\section{Conflicts of Interest}

The author declares no conflicts of interest regarding the publication of this paper. 


\section{References}

Aljalbout, E., Golkov, V., Siddiqui, Y., Strobel, M., \& Cremers, D. (2018). Clustering with Deep Learning: Taxonomy and New Methods. https://arxiv.org/abs/1801.07648

Aumann, H., \& Ruzmaikin, A. (2013). Frequency of Deep Convective Clouds in the Tropical Zone from 10 Years of AIRS Data. Atmospheric Chemistry and Physics, 13, 10795-10806. https://doi.org/10.5194/acp-13-10795-2013

Baldwin, M. P., \& Dunkerton, T. J. (1999). Propagation of the Arctic Oscillation from the Stratosphere to the Troposphere. Journal of Geophysical Research: Atmospheres, 104, 30937-30946. https://doi.org/10.1029/1999JD900445

Bjerknes, J. (1966). A Possible Response of the Atmospheric Hadley Circulation to Equatorial Anomalies of Ocean Temperature. Tellus, 18, 820-829. https://doi.org/10.3402/tellusa.v18i4.9712

Bjerknes, J. (1969). Atmospheric Teleconnections from the Equatorial Pacific. Journal of Physical Oceanography, 97, 163-172. https://doi.org/10.1175/1520-0493(1969)097<0163:ATFTEP >2.3.CO;2

Broccoli, A. J., Lau, N.-C., \& Nath, M. J. (1998). The Cold Ocean and Warm Land Pattern: Model Simulation and Relevance to Climate Change Detection. Journal of Climate, 11, 2743-2763. https://doi.org/10.1175/1520-0442(1998)011<2743:TCOWLP >2.0.CO;2

Buckley, M. W., \& Marshall, J. (2016). Observations, Inferences, and Mechanisms of the Atlantic Meridional Overturning Circulation: A Review. Reviews of Geophysics, 54, 5-63. https://doi.org/10.1002/2015RG000493

Bunimovich, L. (2015). Short-Term and Long-Term Forecast for Chaotic and Random Systems (50 Years after Lorenz's Paper). Nonlinearity, 27, R51. https://doi.org/10.1088/0951-7715/27/9/R51

Chao, W. C. (1985). Sudden Stratospheric Warmings as Catastrophes. Journal of the Atmospheric Sciences, 42, 1631-1646. https://doi.org/10.1175/1520-0469(1985)042<1631:SSWAC >2.0.CO;2

Charney, J. G., \& Darzin, P. G. (1961). Propagation of Planetary-Scale Disturbances from the Lower into the Upper Atmosphere. Journal of Geophysical Research, 66, 83-109. https://doi.org/10.1029/JZ066i001p00083

Cheng, X., \& Wallace, J. M. (1993) Cluster Analysis of the Northern Hemisphere Wintertime 500-hPa Height Field: Spatial Patterns. Journal of the Atmospheric Sciences, 50, 2674-2696. https://doi.org/10.1175/1520-0469(1993)050<2674:CAOTNH >2.0.CO;2

Corti, S., Molteni, F., \& Palmer, T. N. (1999). Signatures of Recent Climate Change in Frequencies of Natural Atmospheric Circulation Regimes. Nature, 398, 799-802. https://doi.org/10.1038/19745

Dai, Y., Feldstein, S. B., Tan, B., \& Lee, S. (2017). Formation Mechanisms of the Pacific North American Teleconnection with and without Its Canonical Tropical Convection Pattern. Journal of Climate, 30, 3139-3155. https://doi.org/10.1175/JCLI-D-16-0411.1

Dickson R. R., \& Namias, J. (1976). North American Influences on the Circulation and Climate of the North Atlantic Sector. Monthly Weather Review, 104, 1255-1265. https://doi.org/10.1175/1520-0493(1976)104<1255:NAIOTC>2.0.CO;2

Ding, C., \& He, X. (2014). K-Means Clustering via Principal Component Analysis. Proceedings of the 21st International Conference on Machine Learning, Banff, Canada, July 2004. https://doi.org/10.1145/1015330.1015408

Donges, J. F., Zou, Y., Marwan, N., \& Kurths, J. (2009). The Backbone of the Climate 
Network. EPL (Europhysics Letters), 87, Article ID: 48007. https://doi.org/10.1209/0295-5075/87/48007

Feynman, J., \& Fougere, P. (1984). Eighty-Eight Year Cycle in Solar Terrestrial Phenomena Confirmed. Journal of Geophysical Research: Space Physics, 89, 3023-3027. https://doi.org/10.1029/JA089iA05p03023

Feynman, J., \& Ruzmaikin, A. (2014). The Centennial Gleissberg Cycle and Its Association with Extended Minima. Journal of Geophysical Research: Space Physics, 119, 6027-6041. https://doi.org/10.1002/2013JA019478

Frankignoul, C., \& Hasselmann, K. (1977). Stochastic Climate Models, Part 2, Application to Sea-Surface Temperature Anomalies and Thermocline Variability. Tellus, 29, 289-305. https://doi.org/10.3402/tellusa.v29i4.11362

Gammaitoni, L. et al. (1998). Stochastic Resonance. Reviews of Modern Physics, 70, 223. https://doi.org/10.1103/RevModPhys.70.223

Gill, A. E. (1982). Atmosphere-Ocean Dynamics. In International Geophysics Series Vol. 30, 662 p). San Diego, CA: Academic Press.

Gray, L. J., Sparrow, S., Juckes, M., O’Neil, A., \& Andrews, D. G. (2003). Flow Regimes in the Winter Stratosphere of the Northern Hemisphere. Quarterly Journal of the Royal Meteorological Society, 129, 925-946. https://doi.org/10.1256/qj.02.82

Haigh, J. D. (1994). The Role of Stratospheric Ozone in Modeling the Solar Radiative Forcing of Climate. Nature, 33, 544-546. https://doi.org/10.1038/370544a0

Hameed, S., \& Lee, J. N. (2005). A Mechanism for Sun-Climate Connection. Geophysical Research Letters, 32, L23817. https://doi.org/10.1029/2005GL024393

Hartigan, J. A. (1975). Clustering Algorithms. Hoboken, NJ: John Wiley \& Sons, Inc.

Hasselmann, K. (1976). Stochastic Climate Models. Part 1. Theory. Tellus, 28, 473-484. https://doi.org/10.3402/tellusa.v28i6.11316

Henley, B. J., Meehl, G., Power, S. B., Folland, C. K., King, A. D., Brown, J. N., Karoly, D. J., Delage, F., Gallant, A. J. E., Freund, M., \& Neukom, R. (2017). Spatial and Temporal Agreement in Climate Model Simulations of the Interdecadal Pacific Oscillation. Environmental Research Letters, 12, Article ID: 044011. https://doi.org/10.1088/1748-9326/aa5cc8

Holton, J. R. (2004). Dynamic Meteorology (p. 347). Amsterdam: Elsevier.

Holton, J. R., \& Mass, C. (1976). Stratospheric Vacillation Cycles. Journal of the Atmospheric Sciences, 33, 2218-2225. https://doi.org/10.1175/1520-0469(1976)033<2218:SVC>2.0.CO;2

Hurrell, J. W. (1995). Decadal Trends in the North Atlantic Oscillation: Regional Temperatures and Precipitation. Science, 269, 676-679.

https://doi.org/10.1126/science.269.5224.676

IPCC (2014). Summary for Policymakers. Intergovernmental Panel on Climate Change (IPCC) Fifth Assessment Report. https://www.ipcc.ch/site/assets/uploads/2018/02/ar4-wg1-spm-1.pdf

Jin, F. F. (1997). An Equatorial Ocean Recharge Paradigm for ENSO. Part I: Conceptual Model. Journal of the Atmospheric Sciences, 54, 811-829. https://doi.org/10.1175/1520-0469(1997)054<0811:AEORPF>2.0.CO;2

Johnson, C., \& Feldstein, S. B. (2010). The Continuum of North Pacific Sea Level Pressure Patterns: Intraseasonal, Interannual, and Interdecadal Variability. Journal of Climate, 23, 851-867. https://doi.org/10.1175/2009JCLI3099.1

Jolliffe, I. T. (2002). Principal Component Analysis. In Series: Springer Series in Statistics 
(2nd ed., 487 p). New York: Springer.

Jolliffe, I. T., \& Cadima, J. (2016). Principal Component Analysis: A Review and Recent Developments. Philosophical Transactions of the Royal Society A, 374, Article ID: 20150202. https://doi.org/10.1098/rsta.2015.0202

Khatiwala, S., Shaw, B. E., \& Cane, M. A. (2001). Enhanced Sensitivity of Persistent Events to Weak Forcing in Dynamical and Stochastic Systems: Implications for Climate Change. Geophysical Research Letters, 28, 2633-2336. https://doi.org/10.1029/2000GL012773

Kimoto, M., \& Ghil, M. (1993). Multiple Flow Regimes in the Northern Hemisphere Winter. Journal of the Atmospheric Sciences, 50, 2645-2673. https://doi.org/10.1175/1520-0469(1993)050<2645:MFRITN >2.0.CO;2

Kodera, K. M. (1995). On the Origin and Nature of the Interannual Variability of the Winter Stratospheric Circulation in the Northern Hemisphere. Journal of Geophysical Research: Atmospheres, 100, 14077-14087. https://doi.org/10.1029/95JD01172

Kosaka, Y., \& Xie, S.-P. (2013). Recent Global-Warming Hiatus Tied Toequatorial Pacific Surface Cooling. Nature, 50, 1403-1407.

Kramers, H. (1940). Brownian Motion in a Field of Force and the Diffusion Model of Chemical Reactions. Physica (Utrecht), 7, 284-304. https://doi.org/10.1016/S0031-8914(40)90098-2

Labitzke, K. (1987). Sunspots, the QBO, and the Stratospheric Temperatures in the North Polar Region. Geophysical Research Letters, 14, 535-537. https://doi.org/10.1029/GL014i005p00535

Labitzke, K. (2004). On the Solar Cycle-QBO Relationship: A Summary. Journal of Atmospheric and Solar-Terrestrial Physics, 67, 45-54.

https://doi.org/10.1016/j.jastp.2004.07.016

Lemke, P. (1977). Stochastic Climate Models, Application to Zonally Averaged Energy Models. Tellus, 29, 385-392. https://doi.org/10.3402/tellusa.v29i5.11371

Limpasuvan, V., \& Hartmann, D. L. (2000). Wave-Maintained Annular Modes of Climate Variability. Journal of Climate, 13, 4414-4429. https://doi.org/10.1175/1520-0442(2000)013<4414:WMAMOC>2.0.CO;2

Lorenz, E. N. (1963). Deterministic Nonperiodic Flow. Journal of the Atmospheric Sciences, 20, 130-141. https://doi.org/10.1175/1520-0469(1963)020<0130:DNF>2.0.CO;2

Loutre, M., Paillard, D., Vimeux, F., \& Cortijo, E. (2004). Does Mean Annual Insolation Have the Potential to Change the Climate? Earth and Planetary Science Letters, 221, 1-14. https://doi.org/10.1016/S0012-821X(04)00108-6

Lovejoy, S. (2013). What Is Climate? EOS, 194, 1-2. https://doi.org/10.1002/2013EO010001

Mantua, N. J., \& Hare, S. R. (2002). The Pacific Decadal Oscillation (A Review). Journal of Oceanography, 58, 35-44. https://doi.org/10.1023/A:1015820616384

Mantua, N., Hare, S., Zhang, Y., Wallace, J., \& Francis, R. C. (1997). A Pacific Interdecadal Climate Oscillation with Impact on Salmon Production. Bulletin of the American Meteorological Society, 178, 1069-3080. https://doi.org/10.1175/1520-0477(1997)078<1069:APICOW>2.0.CO;2

Meehl, G. A., Arblaster, J., Fasullo, J., Hu, A., \& Trenberth, K. (2014). Model-Based Evidence of Deep-Ocean Heat Uptake during Surface-Temperature Hiatus of Global Warming. Nature Climate Change, 4, Article No. 89802.

Min, E., Guo, X., Liu, Q., Zhang, G., Cui, J., \& Long, J. (2018). A Survey of Clustering with Deep Learning: From the Perspective of Network Architecture. IEEE Access, 6, 
39501-39514. https://doi.org/10.1109/ACCESS.2018.2855437

Monahan, A. H. (2000). Nonlinear Principal Component Analysis by Neural Net-Works: Theory and Application to the Lorenz System. Journal of Climatee, 13, 82-835. https://doi.org/10.1175/1520-0442(2000)013<0821:NPCABN >2.0.CO;2

Monahan, A. H., Fyfe, J. C., Ambaum, M. H. P., Stephenson, D. B., \& North, G. R. (2009). Empirical Orthogonal Functions: The Medium Is the Message. Journal of Climate, 22, 6501-6514. https://doi.org/10.1175/2009JCLI3062.1

Newman, M. et al. (2016). The Pacific Decadal Oscillation, Revisited. Bulletin of the American Meteorological Society, 29, 4399-4427. https://doi.org/10.1175/JCLI-D-15-0508.1

Palmer, T. N. (1999). A Nonlinear Dynamical Perspective on Climate Prediction. Journal of Climate, 12, 575-591. https://doi.org/10.1175/1520-0442(1999)012<0575:ANDPOC>2.0.CO;2

Pearson, K. (1901). On Lines and Planes of Closest Fit to Systems of Points in Space. Philosophical Magazine, 2, 559-572. https://doi.org/10.1080/14786440109462720

Picaut, J., Masia, F., \& du Penhoatf, Y. (1997). An Advective-Reflective Conceptual Model for the Oscillatory Nature of the ENSO. Science, 277, 663-666. https://doi.org/10.1126/science.277.5326.663

Quadrelli, R., \& Wallace, J. M. (2004). A Simplified Linear Framework for Interpreting Patterns of Northern Hemisphere Wintertime Climate Variability. Journal of Climate, 17, 3728-3744. https://doi.org/10.1175/1520-0442(2004)017<3728:ASLFFI>2.0.CO;2

Rose, K. (1998). Deterministic Annealing for Clustering, Compression, Classification, Regression, and Related Optimization Problems. Proceedings of the IEEE, 86, 2210-2239. https://doi.org/10.1109/5.726788

Rossby, C.-G. (1939). Relation between Variations in the Intensity of the Zonal Circulation of the Atmosphere and the Displacements of the Semi-Permanent Centers of Action. Journal of Marine Research, 2, 38-55. https://doi.org/10.1357/002224039806649023

Rossby, C.-G. (1941). The Scientific Basis of Modern Meteorology. In Climate and Man (pp. 599-655). Washington DC: US Yearbook of Agriculture.

Rossow, W. B., Tselioudis, G., Polak, A., \& Jakob, C. (2005). Tropical Climate Described as a Distribution of Weather States Indicated by Distinct Mesoscale Cloud Property Mixtures. Geophysical Research Letters, 32, L21812. https://doi.org/10.1029/2005GL024584

Ruzmaikin, A. (1999). Can El Niño Amplify the Solar Forcing of Climate? Geophysical Research Letters, 26, 2255-2258. https://doi.org/10.1029/1999GL900535

Ruzmaikin, A. (2007). Effect of Solar Variability on the Earth's Climate Patterns. Advances in Space Research, 40, 1146-1151. https://doi.org/10.1016/j.asr.2007.01.076

Ruzmaikin, A. (2009). Residence Time Distributions of the Northern Annular Mode. International Journal of Climatology, 29, 2072-2078. https://doi.org/10.1002/joc.1788

Ruzmaikin, A., \& Feynman, J. (2002). Solar Influence on a Major Mode of Atmospheric Variability. Journal of Geophysical Research: Atmospheres, 107, ACL 7-1-ACL 7-11. https://doi.org/10.1029/2001JD001239

Ruzmaikin, A., \& Feynman, J. (2015). The Earth Climate at Minima of Centennial Gleissberg Cycles. Advances in Space Research, 56, 1590-1599.

https://doi.org/10.1016/j.asr.2015.07.010

Ruzmaikin, A., \& Guillaume, A. (2014). Clustering of Atmospheric Data by the Deterministic Annealing. Journal of Atmospheric and Solar-Terrestrial Physics, 120, 121-131. https://doi.org/10.1016/j.jastp.2014.09.009 
Ruzmaikin, A., Cadavid, A. C., \& Lawrence, J. K. (2006a). Stratospheric Wave-Mean Flow Interaction: Simple Modeling. Journal of Atmospheric and Solar-Terrestrial Physics, 68, 1311-1320. https://doi.org/10.1016/j.jastp.2006.05.004

Ruzmaikin, A., Feynman, J., \& Yung, Y. L. (2006b). Is Solar Variability Reflected in the Nile River? Journal of Geophysical Research: Atmospheres, 111, D21114. https://doi.org/10.1029/2006JD007462

Ruzmaikin, A., Feynman, J., Jiang, X., Noone, D., Waple, A., \& Yung, Y. L. (2004a) The Pattern of Northern Hemisphere Temperature during Prolonged Periods of Low Solar Output. Geophysical Research Letters, 31, L12201. https://doi.org/10.1029/2004GL019955

Ruzmaikin, A., Lawrence, J. K., \& Cadavid, A. C. (2003). A Simple Model of Stratospheric Dynamics Including Solar Variability. Journal of Climate, 16, 1593-1600. https://doi.org/10.1175/1520-0442-16.10.1593

Ruzmaikin, A., Lawrence, J. K., \& Cadavid, A. C. (2004b). A Simple Model of Solar Variability Influence on Climate. Advances in Space Sciences, 34, 349-354. https://doi.org/10.1016/j.asr.2003.02.048

Sassen, K., \& Wang, Z. (2008). Classifying Clouds around the Globe with the CloudSat Radar: 1-Year of Results. Geophysical Research Letters, 35, L04805. https://doi.org/10.1029/2007GL032591

Shindell, D., Rind, D., Balachandran, N., Lean, J., \& Lonergan, P. (1999). Solar Cycle Variability, Ozone, and Climate. Science, 284, 305-308. https://doi.org/10.1126/science.284.5412.305

Sohn, B. J., Yeh, S.-W., Schmetz, J., \& Song, H.-J. (2013). Observational Evidences of Walker Circulation Change over the Last 30 Years Contrasting with GCM Results. Climate Dynamics, 40, 1721-1732. https://doi.org/10.1007/s00382-012-1484-Z

Stager, J. C., Ruzmaikin, A., Conway, D., Verburg, P., \& Mason, P. J. (2007). Sunspots, El Niño, and the Levels of Lake Victoria, East Africa. Journal of Geophysical Research: Atmospheres, 112, D15106. https://doi.org/10.1029/2006JD008362

Thompson, D. W. J., \& Wallace, J. M. (1998). The Arctic Oscillation Signature in the Wintertime Geopotential Height and Temperature Fields. Geophysical Research Letters, 25, 1297-1300. https://doi.org/10.1029/98GL00950

Thompson, D. W. J., \& Wallace, J. M. (2001). Regional Climate Impacts of the Northern Hemisphere Annular Mode. Science, 293, 85-89. https://doi.org/10.1126/science.1058958

Timmermann, A. et al. (2018). El Niño and Southern Oscillation Complexity. Nature, 559, 535-545. https://doi.org/10.1038/s41586-018-0252-6

Trenberth, K. E., \& Fasullo, J. T. (2013). An Apparent Hiatus in Global Warming? Earth's Future, 1, 19-32. https://doi.org/10.1002/2013EF000165

Trenberth, K. E., Fasullo, J. T., Branstator, G., \& Phillips, A. S. (2014) Seasonal Aspects of the Recent Pause in Surface Warming. Nature Climate Change, 4, 911-916. https://doi.org/10.1038/nclimate2341

Trouet, V., \& Taylor, A. H. (2009). Multi-Century Variability in the Pacific North American Circulation Pattern Reconstructed from Tree Rings. Climate Dynamics, 35, 953-963. https://doi.org/10.1007/s00382-009-0605-9

van Oldenborgh, G. J., te Raa, L. A., Dijkstra, H. A., \& Philip, S. Y. (2009). Frequency- or Amplitude-Dependent Effects of the Atlantic Meridional Overturning on the Tropical Pacific Ocean. Ocean Science, 15, 293-301. https://doi.org/10.5194/os-5-293-2009

Vecchi, G. A., Soden, B. J., Wittenberg, A. T., Held, I. M., Leetmaa, A. \& Harrison, M. J. 
(2006). Weakening of Tropical Pacific Atmospheric Circulation Due to Anthropogenic Forcing. Nature, 441, 73-76. https://doi.org/10.1038/nature04744

Walker, G. (1928). World Weather. Quarterly Journal of the Royal Meteorological Society, 54, 79-88. https://doi.org/10.1002/qj.49705422601

Walker, G. T., \& Bliss, E. W. (1932). World Weather V. Memoirs of the Royal Meteorological Society, 4, 53-84.

Wallace, J. M., \& Gutzler, D. S. (1981). Teleconnections in the Geopotential Height Field during the Northern Hemisphere Winter. Monthly Weather Review, 109, 784-812. https://doi.org/10.1175/1520-0493(1981)109<0784:TITGHF>2.0.CO;2

Wallace, J. M., Zhang, Y., \& Baju, L. (1996). Interpretation of Interdecadal Trends in Northern Hemisphere Surface Air Temperature. Journal of Climate, 9, 249-260. https://doi.org/10.1175/1520-0442(1996)009<0249:IOITIN>2.0.CO;2

Wallace, J. M., Zhang, Y., \& Renwick, J. A. (1995). Dynamic Contribution to Hemispheric Mean Temperature Trends. Science, 270, 780-783. https://doi.org/10.1126/science.270.5237.780

Wang, C. (2001). A Unified Oscillator Model for the El Niño-Southern Oscillation. $J$ Journal of Climate, 14, 98-115. https://doi.org/10.1175/1520-0442(2001)014<0098:AUOMFT>2.0.CO;2

Weijer, W. et al. (2019). Stability of the Atlantic Meridional Overturning Circulation: A Review and Synthesis. Journal of Geophysical Research: Oceans, 124, 5326-5375. https://doi.org/10.1029/2019JC015083

Wu, Z., Huang, N. E., \& Chen, X. (2009). The Multi-Dimensional Ensemble Empirical Mode Decomposition Method. Advances in Adaptive Data Analysis, 1, 339-372. https://doi.org/10.1142/S1793536909000187

Yoden, S. (1987). Bifurcation Properties of a Stratospheric Vacillation Model. Journal of the Atmospheric Sciences, 44, 1723-1733. https://doi.org/10.1175/1520-0469(1987)044<1723:BPOASV >2.0.CO;2 